\title{
Exploring the Behaviour and Physiology of Juvenile Bonefish (Albula vulpes):
}

\section{Fundamental and Applied Perspectives}

\author{
By
}

Petra Szekeres

B.Sc., Carleton University, 2013

A thesis submitted to the Faculty of Graduate Studies and Research

in partial fulfillment of the requirements for the degree of

\section{Masters of Science}

in

Biology

Carleton University

Ottawa, Ontario

(C)2017, Petra Szekeres 


\section{Dedication}

This thesis is dedicated to my study subject, juvenile bonefish (Albula vulpes).

Thanks for keeping me extremely humble and always on my toes. 


\begin{abstract}
Coastal ecosystems are among the most degraded in the world, which has led to alterations in the structure of nearshore fish communities. These nearshore habitats are home to many fish species, some of which are the juveniles of economically important fish in commercial and recreational fisheries. Bonefish are one such example of a recreationally important sport fish throughout the Caribbean. To date, majority of the research conducted has focused on the adult life stage of bonefish, leaving the juvenile life stage poorly understood. Bonefish in Florida are currently listed as 'nearthreatened' by the IUCN, resulting in calls for a shift in research priorities. In Chapter 2, I experimentally assessed juvenile bonefish shoaling preference when given the opportunity to shoal with conspecifics and other nearshore juvenile fish. I found that overall juvenile bonefish showed a strong tendency to shoal with mojarra (an abundant nearshore fish), rather than conspecifics. In Chapter 3, I determined the consequences of light pollution on the behaviour and physiology of juvenile bonefish. My experiment revealed that while there were no significant changes to swimming behaviour or whole body cortisol, there was an elevation in blood glucose. This research generated novel understanding of the basic ecology of juvenile bonefish, and information on potential impacts caused by a prevalent nearshore anthropogenic disturbance, thus providing a foundational basis for future work.
\end{abstract}




\section{Acknowledgments}

Firstly I would like to thank my supervisor, Dr. Steven Cooke, for providing me with guidance and feedback, as well as allowing me to develop as a student and researcher through endless opportunities during my thesis. I would also like to profusely thank Graham Neely for hundreds of unpaid hours in the field, commiserating and fasting on a beach for two weeks, and becoming the sole care provider of my dog for the past two years. Furthermore, I extend my gratitude to Dr. Jacob Brownscombe for his patient guidance during my statistical analysis and troubleshooting. Other members of the Cooke Lab I would like to acknowledge for various roles during my thesis are Melissa Dick, Shannon Bower, and Dr. Chris Elvidge. I am also grateful to Christopher Haak for his guidance on techniques to locate and capture juvenile bonefish, as well as informing me of previous observations on juvenile bonefish. Thank you to the Cape Eleuthera Institute for the use of their facilities, and the various staff members who supported me during my field seasons. And lastly I would like to extend my gratitude to members of my committee for providing guidance and feedback throughout this entire process. Funding bodies for this research include Bonefish and Tarpon Trust (through the BTT Fellow Program), the Natural Sciences and Engineering Research Council of Canada, and the Canada Research Chairs Program. Animal care approval was administered by the Canadian Council for Animal Care through Carleton University. 


\section{Co-Authorship}

Chapter 2: Juvenile Bonefish (Albula vulpes) Show a Preference to Shoal with Mojarra (Eucinostomus spp.) in the Presence of Conspecifics. Petra Szekeres, Chris R. Haak, Alexander D.M. Wilson, Andy J. Danylchuk, Jacob W. Brownscombe, Aaron D. Shultz, and Steven J. Cooke.

While this study is my own, I acknowledge the help of my co-authors for their contributions throughout the study and write-up. The project was conceived by Szekeres, Haak, Danylchuk and Cooke, with experimental design support from Wilson. Logistical assistance was provided by Shultz. Data analysis was conducted by Szekeres and Brownscombe. Results were interpreted by Szekeres, Haak, Wilson, and Cooke. All writing was conducted by Szekeres, with all co-authors providing feedback on the manuscript. This manuscript is being prepared for submission to a peer reviewed journal.

\section{Chapter 3: Does Coastal Light Pollution Alter the Nocturnal Behaviour and Blood} Physiology of Juvenile Bonefish (Albula vulpes)? Petra Szekeres, Alexander D.M. Wilson, Chris R. Haak, Andy J. Danylchuk, Jacob W. Brownscombe, Chris K. Elvidge, Aaron D. Shultz, Kim BernieGauvin, and Steven J. Cooke.

While this study is my own, I acknowledge the help of my co-authors for their contributions throughout the study and write-up. The project was conceived by Szekeres, Danylchuk, Shultz, and Cooke, with experimental design support from Wilson. Logistical assistance was provided by Shultz. Data analysis was conducted by Szekeres, Brownscombe, and Elvidge. Cortisol analysis was conducted by Bernie-Gauvin. Results were interpreted by Szekeres and Elvidge. All writing was conducted by Szekeres, with all co-authors providing feedback on the manuscript. This manuscript is provisionally accepted by the Bulletin of Marine Science. 


\section{Table of Contents}

Exploring the Behaviour and Physiology of Juvenile Bonefish (Albula vulpes):

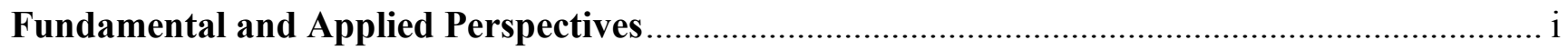

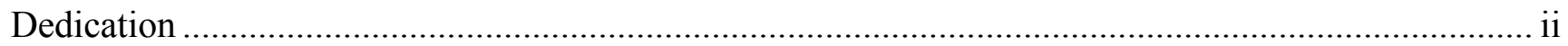

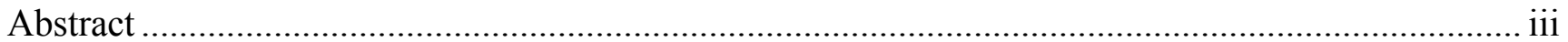

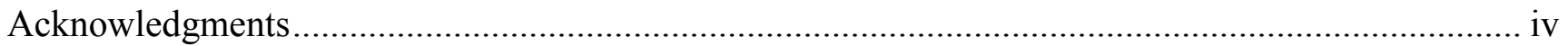

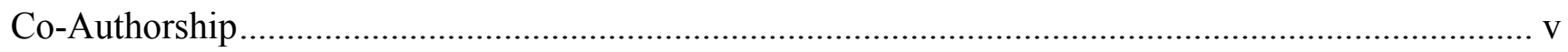

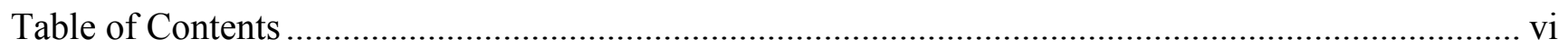

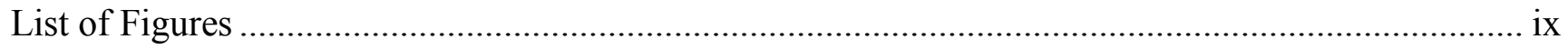

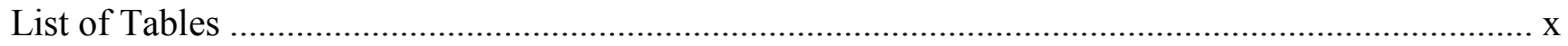

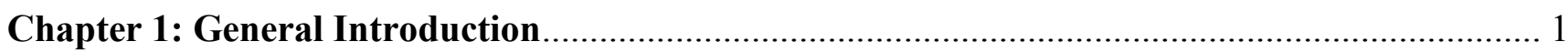

1-1.1: Impact on Juvenile Fish Communities................................................................... 1

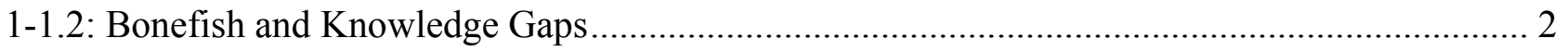

1-1.3: Nearshore Juvenile Fish Habitat Usage .................................................................. 3

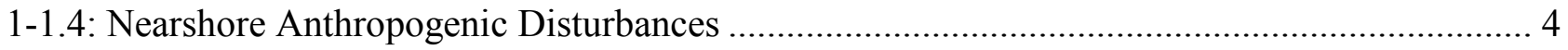

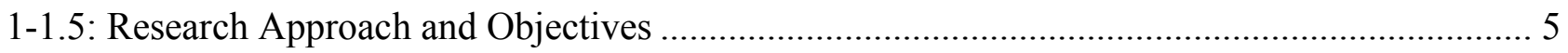

Chapter 2: Juvenile bonefish (Albula vulpes) show a preference to shoal with mojarra

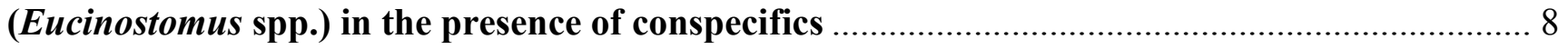

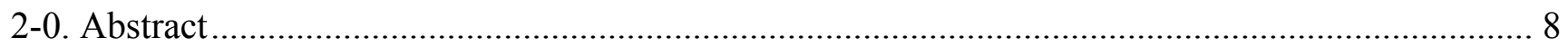

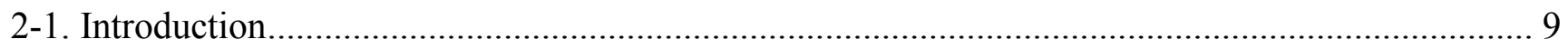

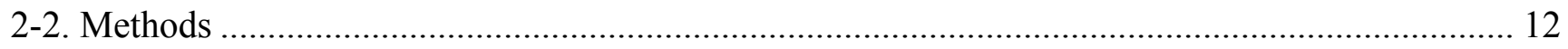




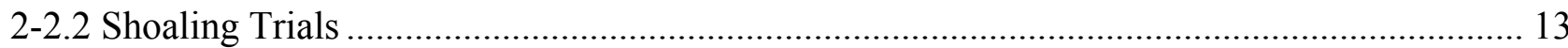

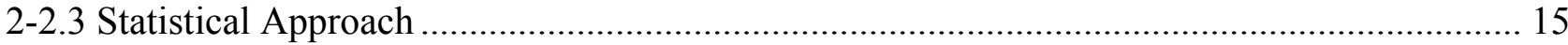

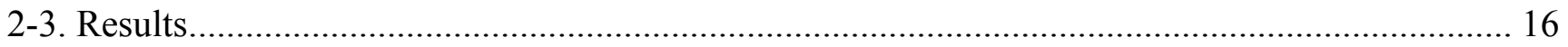

2-3.1 Bonefish and Mojarra Stimulus Shoals................................................................. 16

2-3.2 Bonefish and Pilchard Stimulus Shoals ................................................................ 17

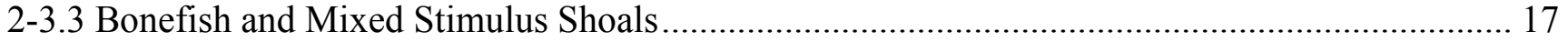

2-3.4 Mojarra and Mixed Stimulus Shoals......................................................................... 18

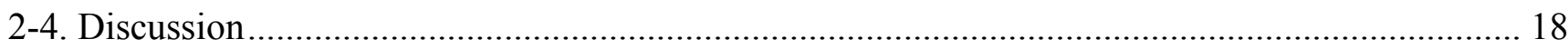

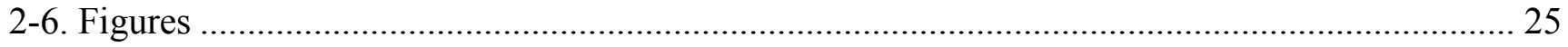

Chapter 3: Does Coastal Light Pollution Alter the Nocturnal Behaviour and Blood Physiology of

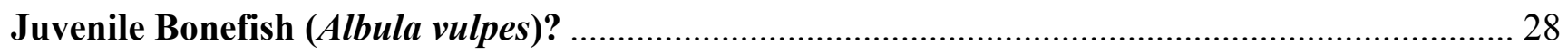

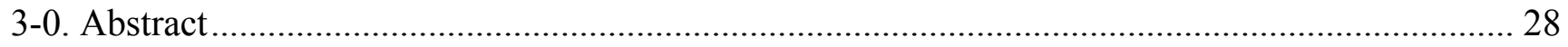

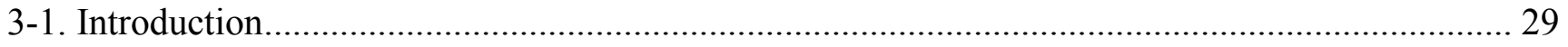

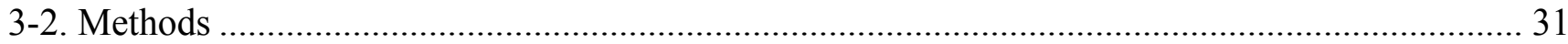

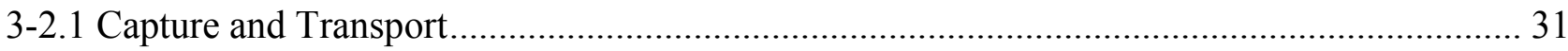

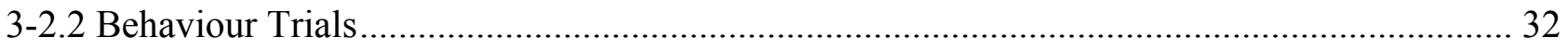

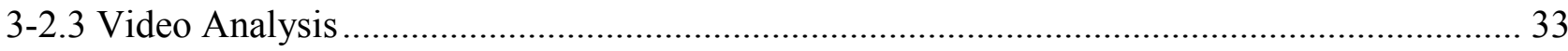

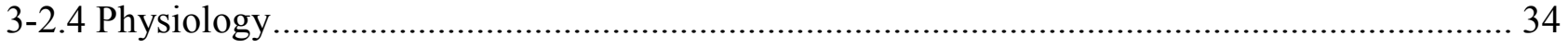

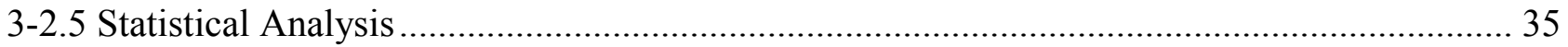

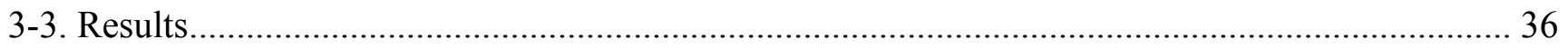


3-3.1 Behaviour

3-3.2 Physiology.

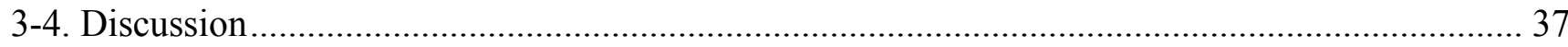

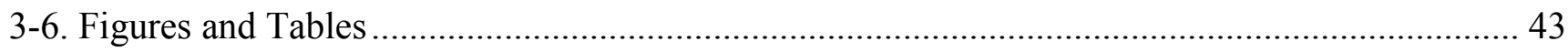

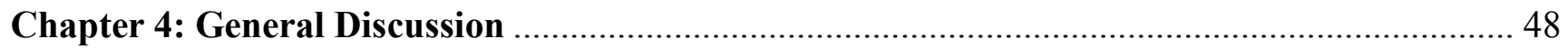

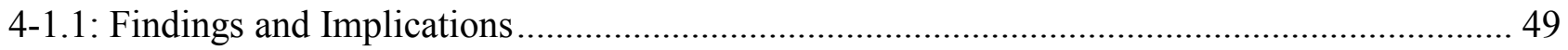

4-1.2: Future Research Opportunities .................................................................................. 51

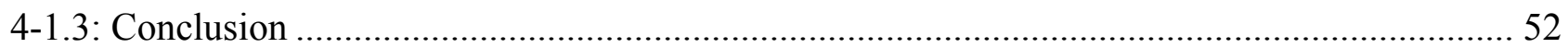

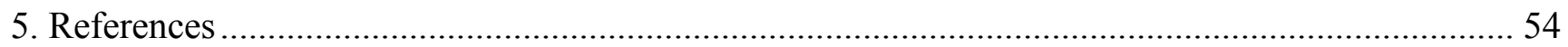




\section{List of Figures}

Fig. 2-1 A map of southern Eleuthera, The Bahamas (developed using Google Earth Pro). The star denotes the capture and collection site of juvenile bonefish in Rock Sound, and the triangle denotes the location of the Cape Eleuthera Institute wet lab.

Fig. 2-2 Mean responses $( \pm \mathrm{SE})$ of time focal bonefish spent (in seconds) shoaling with other bonefish or mojarra (2a), and time spent (in seconds) shoaling with bonefish or pilchard (2b) in stimulus shoal sizes of $1 \times 1,2 \times 2,4 \times 4,8 \times 8$. Asterisks $(*)$ denote significant differences between species in each shoal size.

Fig. 2-3 Box-and-whisker plot of time focal bonefish spent (in seconds) shoaling with four bonefish or a mixed shoal of two bonefish and two mojarra (2-3a), and time focal bonefish spent (in seconds) shoaling with four mojarra or a mixed shoal of two bonefish and two mojarra(2-3b). The horizontal bold line within the box indicates the median of the data, while the boundaries of the box indicate the $25^{\text {th }}$ and $75^{\text {th }}$ percentiles, and the whiskers denote upper and lower data points outside the middle $50^{\text {th }}$ percentile. Asterisks $\left(^{*}\right)$ denote significant differences between single species and mixed species shoals.

Fig. 3-1 Diagram of the experimental set up to assess the behavioural response of juvenile bonefish to experimental lighting conditions (i.e., constant and intermittent lighting). Cameras were mounted above each individual arena, and each arena was further subdivided on the bottom of the tank with lines to measure horizontal distance traveled.

Fig. 3-2 Mean responses $( \pm \mathrm{SE})$ in (a) distance traveled (cm), (b) $90^{\circ}$ turns, (c) freeze events and (d) burst events demonstrated by juvenile bonefish (Albula vulpes) during two hr light treatment periods (open bars) and two hr ambient/dark recovery periods (shaded bars). Light periods consisted of a 
daytime control (Day), nighttime control (Night), constant light at night (Night C) and intermittent light at night (Night I).

Fig. 3-3 Boxplots illustrating median, $25^{\text {th }}$ and $75^{\text {th }}$ quartiles, and $95 \%$ CI blood glucose concentrations (mmol/L) in wild-caught, captive juvenile bonefish (Albula vulpes) immediately following exposure to constant, intermittent ( $1 \mathrm{~min}$ of constant light every $10 \mathrm{~min}$ ), or no artificial light (control) treatments between $20 \mathrm{~h} 00-04 \mathrm{~h} 00$. Asterisk $\left(^{*}\right)$ denotes significant pairwise differences between treatments from the Kruskal-Wallis test with Nemenyi test post hoc $(\mathrm{p}<0.05)$.

\section{List of Tables}

Table 3-1 Repeated measures two-way analysis of variance in four behavioural responses in juvenile bonefish (Albula vulpes) during or after (Time) exposure to constant, intermittent light and a dark control at night and a daytime ambient light control (Treatment). Bold values indicate statistical significance $(\mathrm{p}<0.05)$

Table 3-2 Variance component analysis expressing the relative contributions (percent) of individual variability and treatment effects on observed behavioural responses of juvenile bonefish (Albula vulpes) exposed to constant, intermittent and no light at night and a daytime ambient light control. 


\section{Chapter 1: General Introduction}

Coastal ecosystems offer a wide array of ecological and economic services globally, ranging from fisheries resources, shoreline protection from erosion and severe storms, and provision of spawning and nursery grounds for a number of marine species (Burke et al. 2000; Martínez et al. 2007; Barbier \& Hacker 2011). A remarkable number of marine animals rely on coastal ecosystems during various stages of their lives for feeding, shelter, spawning, and as nursery grounds (Kennish 2002; Bilkovic \& Roggero 2008). In fact, it is estimated that nearly $80 \%$ of harvestable marine fish are either directly or indirectly dependent on mangrove habitats during various life stages (O’Sullivan 2005; Ellison 2008). In recent decades, these coastal marine ecosystems have been the subject of overwhelming and increasing amounts of anthropogenic pressure through coastal development and pollution. Indeed, they are now among the most heavily altered and degraded ecosystems in the world (Halpern et al. 2008). Tropical and subtropical coastal ecosystems are particularly sensitive to disturbance (e.g., land use alteration, mangrove removal), and are becoming increasingly degraded by coastal development (Siung-Chang 1997; Valiela et al. 2001; Polidoro et al. 2010). Mangroves, seagrasses, and coral reefs all provide crucial habitat for juvenile fish, and have substantially decreased globally in area cover over the last several decades (35\%, Valiela et al. 2001; 29\%, Waycott et al. 2009; and 27\%, Wilkinson 2000 respectively).

\section{1-1.1: Impact on Juvenile Fish Communities}

Habitat degradation has direct impacts on the nearby fish communities relying on these ecosystems (Jackson et al. 2001; Bilkovic \& Roggero 2008). A large proportion of fish communities in the immediate nearshore areas are comprised of juvenile and sub-adult life stages 
(Nagelkerken et al. 2000; Gullström et al. 2008). It is hypothesized that juvenile fish primarily utilize nearshore habitats due to lower predation pressure (i.e., restrictions to predator size based on water depth and mangrove structures), thereby resulting in less energy allocated towards predator avoidance behaviours (Baker \& Sheaves 2007), as well as enhanced foraging opportunities (Paterson \& Whitfield 2000; Munsch et al. 2016). Juvenile fish are known to utilize nearshore habitats as key nursery sites (Paterson \& Whitfield 2000; Seitz et al. 2014), and are particularly sensitive to disturbances during this sensitive life stage (Laegdsgaard \& Johnson 2001). It is estimated that there has been a global decline of $69 \%$ of juvenile fish nursery habitats (i.e., seagrass beds, wetlands, oyster reefs; Lotze et al. 2006; Worm et al. 2006). Due to the combined sensitivities of both juvenile fish and the habitats they utilize in the tropics and subtropics, there is a need to better understand the ecology and impacts of anthropogenic disturbances on juvenile fish in these systems.

\section{1-1.2: Bonefish and Knowledge Gaps}

The juvenile fish communities in tropical and subtropical nearshore habitats are comprised of a mix of economically important species (Peters et al. 1998; Reis-Filho et al. 2011; Jud et al. 2011), as well as forage fish and other resident fish species (Sheridan 1992). Bonefish (Albula vulpes) are an economically important species that are well-researched as adults, but with very few resources being mobilized to investigate the juvenile life stage. As adults, bonefish are worth an estimated \$141 million USD in the Bahamas; catch-and-release flats fishing tourism comprises up to $80 \%$ of total tourist direct expenditures on the different islands of The Bahamas (Fedler 2010). Due to this economic importance, adult bonefish research has had a strong focus on the physiological and behavioural consequences of catch-and-release angling (e.g., Cooke \& Philipp 2004; Danylchuk et al. 2007; Brownscombe et al. 2013), as well as understanding their 
movement and biology (Murchie et al. 2013; Szekeres et al. 2014; Nowell et al. 2015). Although it is often the charismatic species, such as bonefish, that receive research attention beyond understanding basic ecology, the heretofore understated ecological and economic importance of forage fish and prey species are beginning to garner the attention of the scientific community as well (Hannesson et al. 2009; Hannesson \& Herrick 2010).

Earliest research on bonefish focused on the larval leptocephali stage (e.g., Fitch 1950; Rasquin 1955), while recent research has focused on sub-adult and adult life stages. Therefore, a crucial knowledge gap exists between when larval bonefish metamorphose and when they become sub-adults - thus, the entirety of their juvenile life stage. This substantial knowledge gap has led to a limited understanding of juvenile bonefish biology and ecology. In addition, locating juvenile bonefish is far more difficult due to their small size and apparent shoaling differences as juveniles than as adults. Indeed, juvenile bonefish have proven very difficult to locate along the Florida Keys, and following two decades of exhaustive efforts, have not been caught in any substantial numbers (Adams et al. 2008; Snodgrass et al. 2008). Furthermore, bonefish have recently been designated as 'near-threatened' by the International Union for Conservation of Nature (IUCN) (Adams et al. 2014), prompting research to be conducted along a broader spectrum. This new designation has stimulated the need for a holistic understanding of bonefish across various life stages, thus motivating research to be conducted on their most understudied life stage: the juvenile life stage.

\section{1-1.3: Nearshore Juvenile Fish Habitat Usage}

As many fish species of various life stages utilize tropical and subtropical nearshore habitats, there is often substantial habitat overlap (Sogard et al. 1989). However, due to different 
feeding modes and habitat requirements, these habitats are often partitioned further between and within species; the use of these different microhabitats may predispose species to have interspecific associations with different species of fish in the same functional group (Hyndes et al. 1997; Schafer et al. 2002). Juvenile bonefish, pilchard (Harengula jaguana), and mojarra (Eucinostomus spp.) all occupy the same nearshore habitats, although the ways in which they utilize these habitats presumably differ. Juvenile bonefish and mojarra are demersal benthivorous fish (Teixeira \& Helmer 1998; Reis-Filho et al. 2011), and both appear to occupy the same microhabitats, while pilchard are planktivorous fish and occupy the upper region of the water column (Modde \& Ross 1983; Pierce et al. 2001). In addition to the evidence of the contrasting foraging modes of pilchard to bonefish and mojarra, anecdotal evidence from field sampling also supports that juvenile bonefish and mojarra are caught together with extremely high frequency, while the instances of juvenile bonefish being caught with pilchard are uncommon (Chris Haak, unpubl. data). These field observations have raised several questions with regards to the apparent association between juvenile bonefish and mojarra.

\section{1-1.4: Nearshore Anthropogenic Disturbances}

In addition to the knowledge gaps surrounding juvenile bonefish inter- and intra-specific relationships, the impacts of coastal development on juvenile bonefish behaviour are also entirely unknown. Due to their apparent reliance on immediate nearshore habitats, juvenile bonefish are at the interface of potential anthropogenic disturbances from coastal development. These disturbances include, but are not limited to, excess nutrient output and sedimentation, habitat alteration, as well as the lesser understood impacts of coastal development (Bilkovic \& Roggero 2008; Poliodoro et al. 2010). A historically underrepresented pollutant emerging from coastal development is artificial light pollution (Vinogradova et al. 2009). Although recent 
research on the consequences of light pollution on terrestrial animals has found disruptions to spatial orientation, foraging patterns, migration, reproduction, predation, and communication (all reviewed in Longcore \& Rich 2004), there has been little research on the effects of coastal light pollution on nearshore marine organisms (with the exception of hatchling sea turtles; Salmon et al. 1995). Coastal ecological light pollution (described in Longcore \& Rich 2004) offers very little respite to various species and life stages of fish, such as juvenile bonefish, that rely on nearshore ecosystems for food and refuge (Munsch et al. 2016). This is particularly true in areas of high coastal development, such as the southeastern coast of Florida where essentially all coastline has been developed (Finkl \& Charlier 2003). Combined with the recent IUCN designation of bonefish as 'near threatened', and the relative difficulty of locating juvenile bonefish along the same developed coastlines, studying the consequences of light pollution on juvenile bonefish is highly relevant.

\section{1-1.5: Research Approach and Objectives}

As sub-adult and adult bonefish are so economically important for tropical coastal nations, it is critical to advance our understanding of their preceding juvenile life stage. Accordingly, the focus of this thesis was to gain insight into the behavioural ecology of juvenile bonefish, with regards to their shoaling responses to conspecifics and similar species in the same habitat (i.e., mojarra, pilchard), as well as their response to impacts of coastal light pollution. Conducting research on the basic ecology of juvenile bonefish will give insights into the requirements of this life stage, and following subsequent research may help to determine whether juvenile bonefish have special conservation needs beyond those of adults. The general approach of both chapters was to conduct lab-based experimental studies, using a combination of behavioural and physiological measures to gain an understanding of: (i) juvenile bonefish 
shoaling behaviour relative to various nearshore fish sharing the same habitats, and (ii) the impact of artificial light pollution on juvenile bonefish behaviour and physiology. For Chapter 2, in my shoaling studies I determined whether juvenile bonefish are so frequently caught among mojarra due solely to the large and widespread abundance of mojarra, or whether juvenile bonefish are actively affiliating in a multi-species shoal with mojarra. Additionally, I explored how factors like shoal size, and mojarra proportions play into the shoal selectivity of juvenile bonefish. To this end, the objectives of this study were to determine whether juvenile bonefish prefer to shoal with conspecifics or mojarra, conspecifics or pilchard, and whether shoal size plays a significant role; additionally I determined their shoal preference when given the choice between conspecifics, mojarra, or a mixed shoal of bonefish and mojarra. In Chapter 3, my objective was to determine the acute effects of ecologically relevant light pollution on juvenile bonefish behaviour and physiology. I examined juvenile bonefish swimming behaviour when exposed to light pollution, and measured their blood glucose levels post-exposure, and evaluated whole body cortisol. Wild-caught juvenile bonefish were exposed to two ecologically relevant light treatments: constant simulated street lighting (high pressure sodium) and intermittent car headlights (H4 halogen), and their responses were compared to control animals (no artificial light). This study will add to an emerging body of literature on light pollution and act as the first study to specifically address this issue in a coastal marine fish.

This thesis will begin addressing the knowledge gaps that exist in our understanding of bonefish behaviour. Conducting research on juvenile bonefish is especially important, due in part to the economic importance of adult bonefish (particularly to small island nations), and also given the sensitive habitats juvenile bonefish occupy. My thesis provides a necessary first glimpse into this important life stage of bonefish; the research from my thesis generated novel 
results to begin understanding the basic ecology of juvenile bonefish, as well as the potential impacts of coastal development on their behaviour and physiology. Following additional research, there may be evidence to suggest juvenile bonefish have differing requirements from their adult counterparts, thereby necessitating juvenile bonefish inclusion in future management decisions and conservation programs. 


\section{Chapter 2: Juvenile Bonefish (Albula vulpes) Show a Preference to Shoal with Mojarra (Eucinostomus spp.) in the Presence of Conspecifics}

\section{2-0. Abstract}

There are several benefits derived from social behaviour in animals, such as enhanced information transfer, increased foraging opportunities, and predator avoidance. Animal grouping occurs over various taxa, with multi-species grouping taking place across nearly as many taxa as single-species grouping. Fish are commonly used in the study of animal social behaviour, with shoaling or schooling behaviour occurring in approximately $50 \%$ of all fish species at some point in their development. The juvenile life stage of bonefish (Albula vulpes) is poorly understood, with no experimental evidence of their shoaling associations despite anecdotal data suggesting that they tend to be captured alongside mojarra (Eucinostomus spp). This study assessed the shoaling preferences of focal juvenile bonefish $(n=25)$ when given the choice between: (i) conspecifics or mojarra, and (ii) conspecifics or pilchard (Harengula jaguana), in shoal sizes of one, two, four, and eight. In addition, juvenile bonefish shoaling preference was further examined when given the choice between a mixed shoal (two conspecifics, two mojarra) as an alternative choice to single species shoals of either (iii) four conspecifics, or (iv) four mojarra. The results from this study suggest that juvenile bonefish have a strong association with mojarra, spending significantly more time with them than conspecifics in the majority of trials. Additionally, focal fish showed no preference when offered stimulus shoals of conspecifics or pilchard, regardless of shoal size. Lastly, for the two mixed shoal trials, focal fish spent significantly more time wherever there was a higher proportion of mojarra. Future research is required to understand the underlying mechanisms responsible for juvenile bonefish associations with mojarra. 


\section{2-1. Introduction}

Sociality is an integral part of animal behaviour across various taxa, commonly presenting itself in the form of group living (Krause \& Ruxton 2002). Social behaviours of group living aid in enhanced foraging opportunities (Clark \& Mangal 1986; Sazima et al. 2007), predator avoidance and vigilance (Turner \& Pitcher 1986; Elgar 1989), centralized information transfer (Dall \& Johnstone 2002; Couzin et al. 2005), cooperative group hunting (Packer \& Ruttan 1988; Pitman \& Durban 2012), mate choice and cooperative breeding (Amundsen \& Forsgren 2001; Clutton-Brock 2002), and reduce the energetic costs of movement (Weimerskirch et al. 2001; Marras et al. 2015). However, these benefits are often accompanied by various costs, including increased parasite and disease transmission, resource competition (i.e., food, shelter), mate infidelity, and conspicuousness (all reviewed in Krause \& Ruxton 2002).

Heretofore, the most widely researched aspects of group living are those focused on the advantages of grouping, with a particular focus on foraging and anti-predator benefits (Székely et al. 1989; Krause \& Ruxton 2002; Sridhar et al. 2009). Some associated fitness benefits of grouping are increased foraging success due to the collective food-finding abilities of a group, or by capitalizing and gaining information from individuals within the group that have more local foraging knowledge (Lachlan et al. 1998; Giraldeau \& Beauchamp 1999). Furthermore, individuals may experience anti-predator benefits of attack abatement (a combination of predator avoidance and dilution effect), predator confusion, increased vigilance leading to greater information transfer, or a combination of some, or all, of these advantages (Dall \& Johnstone 2002). The use of these information sharing systems has a net benefit for individuals in groups, reducing their 'ecological uncertainty' (Stensland et al. 2003; Dall et al. 2005). In addition to the foraging and anti-predator benefits observed in intraspecific groups, the occurrence of 
interspecific (i.e., multi-species) groups also mediates some competitive costs of intraspecific group living (Labropoulou \& Eleftheriou 1997; Bolnick 2001; Wolf \& Weissing 2012).

Multi-species groups exist across nearly as many taxa as do single-species groups (Hoare et al. 2000) and generally receive similar benefits of enhanced food finding, increased vigilance, and social learning through information sharing, which is particularly crucial for animals whose prey have a patchy distribution (a common concern for both avian flocks and fish shoals; Lukoschek \& McCormick 2000; Silverman et al. 2004). In addition to the same benefits derived from single-species groups, multi-species groups often have the added benefit of reducing many competitive costs of grouping (Krause \& Ruxton 2002). The primary cost of grouping is resource competition; however, in multi-species groups, it is not uncommon for constituents to establish different niches, thereby increasing their fitness while reducing interspecific competition (Labropoulou \& Eleftheriou 1997; Stewart et al. 2003; Krajewski et al. 2006). Multi-species grouping advantages may also be present in the form of prey restriction based on morphological differences in feeding apparatus (e.g., Aguirre et al. 2002), temporally divergent foraging activity (e.g., Albrecht \& Gotelli 2001), prey flushing and kleptoparasitism (e.g., Sridhar et al. 2009), and mate choice (e.g., Veen et al. 2001), among others.

Fishes are commonly used in the study of animal social behaviour, with shoaling or schooling behaviour occurring in approximately $50 \%$ of all fish species at some point in their development (Radakov 1973; Pavlov \& Kasumyan 2000). Multi-species shoaling has been widely documented in tropical marine species (Hoare \& Krause 2003), with an emphasis on reef and nearshore systems, likely due to logistical challenges of observing pelagic species in the wild (Wilson \& Krause 2013; Domenici et al. 2014). As tropical nearshore marine habitats often behave as fish nurseries and spawning grounds (Beck et al. 2001; Laegdsgaard \& Johnson 2001), 
it is not unusual for a variety of species to be found utilizing the same habitats (Nagelkerken et al. 2000; Layman \& Silliman 2002) to enhance foraging opportunities while eliminating the presence of larger predators (Patterson \& Whitfield 2000; Munsch et al. 2016).

As adults, bonefish (Albula vulpes) are an economically important species in The Bahamas through the catch-and-release angling industry (\$141 million USD annually; Fedler 2010). Juvenile bonefish are found in nearshore habitats, as are mojarra (Eucinostomus spp.) and pilchard (Harengula jaguana; Sogard et al. 1989). Mojarra and pilchard are far more abundant in neritic shallow habitats than the juvenile life stage of near-threatened bonefish (Sogard et al. 1989; Adams et al. 2014), and each species occupy distinct regions of the water column and utilize different foraging techniques (Vega-Cendejas et al. 1994; Layman \&Silliman 2002). For example, juvenile bonefish and mojarra are demersal fish that primarily prey on benthic invertebrates found either buried in- or living on the substrate (Teixeira \& Helmer 1998; ReisFilho et al. 2011), while juvenile pilchard are zooplanktivorous, and as such, their time is primarily spent in the upper reaches of the water column (Modde \& Ross 1983; Pierce et al. 2001). These functional group characteristics also align with field observations and cooccurrence indices of mojarra and bonefish, while there is little observational evidence that pilchard also co-occur with these species (Chris Haak, unpubl. data). Anecdotally, juvenile bonefish are primarily captured with large shoals of mojarra and rarely caught with aggregations of other fish that utilize similar habitat (Chris Haak, unpubl. data), such as juvenile pilchard. This suggests that there may be more affiliative interactions between juvenile bonefish and mojarra than what might be expected based simply on sharing similar habitat preferences.

These prior observations raise several questions with regards to this repeated, seemingly non-random behaviour. I aimed to determine whether juvenile bonefish were shoaling with 
mojarra due to chance and the relative abundance of mojarra, or if they were actively engaging in multi-species shoals rather than shoaling with conspecifics. Moreover, I was interested in how factors like shoal size, functional groups, and phenotypic similarity influence selectivity. To this

end, the objectives of this study were to determine whether juvenile bonefish prefer to shoal with conspecifics, mojarra, or pilchard, and whether shoal size plays a significant role. Pilchard were chosen due to their abundance, as well as phenotypic and morphological similarities to juvenile bonefish (i.e., fusiform body shape, pigmentation). Lastly, juvenile bonefish shoal preference was considered when offered a conspecific shoal, a mojarra shoal, or multi-species shoal of juvenile bonefish and mojarra. Studying the shoaling preferences of juvenile bonefish will provide insights into their behaviour and basic ecology requirements, serving to inform on some knowledge gaps that exist for the juvenile life stage.

\section{2-2. Methods}

\section{2-2.1 Capture, Transport, and Holding}

The study was conducted in south Eleuthera, The Bahamas (N 2450'05" and W $\left.76^{\circ} 20^{\prime} 32^{\prime \prime}\right)$ at the Cape Eleuthera Institute (CEI) during June and July of 2015. Twenty five juvenile bonefish $($ mean $=70.2 \pm 15 \mathrm{~mm}$ SD fork length; range 50-110 mm) were collected from Rock Sound to be the focal fish in the shoaling study (Fig. 2-1). Mojarra (mean $=67.8 \pm 7.5 \mathrm{~mm}$ SD fork length; range 58-81 mm), scaled pilchard (mean $=73.2 \pm 7.1 \mathrm{~mm}$ SD fork length; range 62-90 $\mathrm{mm}$ ), and additional juvenile bonefish (mean $=70.5 \pm 9 \mathrm{~mm}$ SD fork length; range 55-85 mm) were similarly collected; these three species made up the respective stimulus fish shoals. Fish were caught using spot seining techniques, whereby nearshore habitats (<1 m depth) were visually assessed, and when the species of interest were identified, a seine net (15.25 m 
length $\times 1.22 \mathrm{~m}$ height, $0.6 \mathrm{~cm}$ mesh size) was used to capture them. Captured fish were then transferred into flow-through net pens $(1.50 \mathrm{~m}$ length $\times 0.7 \mathrm{~m}$ width $\times 1.20 \mathrm{~m}$ height $)$ while more fish were collected, before being relocated to coolers $(90 \mathrm{~cm}$ length $\times 35 \mathrm{~cm}$ width $\times 20 \mathrm{~cm}$ height; $63 \mathrm{~L}$ ) on the boat for transportation. All fish transfers were done without exposing fish to air or causing net abrasion (Murchie et al. 2009; Cook et al. 2015). Upon arrival at the wet lab facility at CEI, the juvenile bonefish focal fish (herein referred to as 'focal fish') were held in individual pens $(35 \mathrm{~cm}$ length $\times 30 \mathrm{~cm}$ width $\times 20 \mathrm{~cm}$ height; $0.3 \mathrm{~cm}$ mesh size) to follow the same individuals throughout the entire study without having to handle individual fish more than necessary, or mark these small fish. The individual holding pens were set in tanks $(155 \mathrm{~cm}$ diameter $\times 25 \mathrm{~cm}$ height; $472 \mathrm{~L}$ ) that were aerated and continuously supplied with fresh seawater $(10 \mathrm{~L} / \mathrm{min})$ at ambient water temperatures $\left(28.6 \pm 2.4{ }^{\circ} \mathrm{C} \mathrm{SD}\right)$, thus did not induce visual or olfactory isolation. The three species of stimulus fish were held in separate tanks with their conspecifics $(155 \mathrm{~cm}$ diameter $\times 25 \mathrm{~cm}$ height; $472 \mathrm{~L})$. All fish were held for a minimum of $48 \mathrm{hr}$ prior to experimentation.

\section{2-2.2 Shoaling Trials}

Each focal fish $(\mathrm{n}=25)$ was observed in four trials, with a total of ten stimulus shoal combinations over the four trials. The structure of four trials of the experiment was to allow each focal fish the option of shoaling with: (i) conspecifics or mojarra; (ii) conspecifics or pilchard; (iii) conspecifics or a mixed shoal with equal mojarra and bonefish; and (iv) mojarra or a mixed shoal with equal mojarra and bonefish. For the conspecific and mojarra, as well as the conspecific or pilchard trials, focal fish shoaling preference was examined with four stimulus shoal combinations, with either one-, two-, four-, or eight- fish in each stimulus shoal (i.e., $1 \times 1$, $2 \times 2,4 \times 4,8 \times 8$ ); that is, one mojarra or one bonefish, two mojarra or two bonefish, one pilchard 
or one bonefish, and so on. Furthermore, I was interested in determining the shoaling tendencies of focal fish when given the choice to shoal with either four conspecifics or a mixed shoal of two conspecifics and two mojarra; conversely, with a shoal of four mojarra or a shoal of two conspecifics and two mojarra (herein referred to as a 'mixed shoal').

For the shoaling trials, a Y- maze $(70 \mathrm{~cm}$ arm lengths $\times 18 \mathrm{~cm}$ width $\times 25 \mathrm{~cm}$ height $)$ was utilized as the experimental arena. Methods were largely modified from Wright and Krause (2006). One arm of the Y-maze was the focal fish release area, with another arm housing one of the stimulus shoals, and the final arm housing the other stimulus shoal. Each stimulus shoal was in a one-way glass transparent bin $(18 \mathrm{~cm}$ length $\times 18 \mathrm{~cm}$ width $\times 20 \mathrm{~cm}$ height; $6.5 \mathrm{~L})$ at the end of each respective arm, with a daylight emulating light bulb (Lighting Science Group, Satellite Beach, Florida, United States of America; 60 watt) $30 \mathrm{~cm}$ above each stimulus fish bin for greater efficacy of the one-way glass (modifications made from Wright \& Krause 2006). There was no olfactory exchange between the focal fish and stimulus shoals; due to the one-way glass, focal fish were able to see the stimulus shoals without the opposite occurring (Wright \& Krause 2006). Stimulus shoals were given $1 \mathrm{hr}$ to acclimate to holding bins prior to experimentation. A focal fish was removed from its individual holding pen and first placed in an opaque beaker $(14 \mathrm{~cm}$ diameter $\times 15 \mathrm{~cm}$ height; $2.3 \mathrm{~L})$ with water from the test tank and left to acclimate for $10 \mathrm{~min}$. After $10 \mathrm{~min}$, the fish was gently poured into a transparent cylinder $(15 \mathrm{~cm}$ diameter $\times$ $30 \mathrm{~cm}$ height) in the empty arm of the Y-maze and left to acclimate for another $5 \mathrm{~min}$. Following this final acclimatization period, the focal fish was released and observed via live video feed for 20 min (DVR9-4200 9 Channel 960H Digital Video Recorder and PRO-642 Cameras; Swann Communications U.S.A Inc.; Santa Fe Springs, California, United States of America). The observer recorded seconds spent close-shoaling with either stimulus shoal, quantified as being 
within approximately 2 body lengths $(20 \mathrm{~cm})$ of the stimulus shoal (Pitcher 1986). After the 20 min trial, the focal fish was moved back to its individual pen and the process was repeated with another randomly selected focal fish. Stimulus shoal position in the Y-maze was changed every five trials, with stimulus shoal individuals also being changed occasionally to prevent shoaling bias (Wright \& Krause 2006); the focal fish were tested in a random order at the start of each day.

\section{2-2.3 Statistical Approach}

All analyses were conducted using R version 3.3.1 (R Core Team 2016). For both (i) bonefish or mojarra trials, and (ii) bonefish or pilchard trials, linear mixed effects models (LME) were fit to square root transformed time (sec) spent with each species to meet the assumptions of normality. Shoal species (bonefish or mojarra; bonefish or pilchard) and shoal size $(1 \times 1,2 \times 2$, $4 \times 4,8 \times 8$ ) were included as predictors, as was the interaction between shoal species and shoal size, and individual focal fish was included as a random effect. A backward model selection approach was used to determine significant predictors by comparing full models to those with reduced terms with log-ratio tests (Zuur et al. 2009). When significant predictors were identified, a Bonferroni post-hoc test was used to determine which stimulus shoal species and shoal sizes were significantly different. Models were validated following the procedure outlined in Zuur et al. (2009).

For the mixed shoal experiments, time focal bonefish spent with (iii) conspecifics or a mixed shoal with equal mojarra and bonefish, and (iv) mojarra or a mixed shoal with equal mojarra and bonefish were analyzed using paired t-tests. Parametric assumptions were checked 
prior to analysis and the data were square root transformed to meet the assumption of normality.

For all analyses, data were considered significant at an alpha of 0.05 unless correction applied.

\section{2-3. Results}

\section{2-3.1 Bonefish and Mojarra Stimulus Shoals}

During the trials with bonefish and mojarra as the stimulus shoal choices, focal fish spent more time shoaling with mojarra than conspecifics (Fig. 2-2a). In general, focal fish spent more time shoaling with mojarra than conspecifics; focal fish spent over three quarters of trial durations engaged in a shoal, with $73 \%$ of that time spent shoaling with mojarra. In many instances, focal fish would explore the experimental arena (i.e., investigate both shoal options) and then choose to stay close-shoaling with mojarra. There was a significant interaction between stimulus shoal species and shoal size $\left(\mathrm{LME} ; X^{2}=19.3, \mathrm{p}<0.001\right)$. Bonefish spent significantly more time with mojarra in shoal sizes of one, four, and eight (Tukey's HSD; $p<0.001$ ); however, there was no significant difference in time spent with either species in shoal sizes of two (Tukey’s HSD; $p=1.0$; Fig. 2-2a). Two LME models (one with Fish ID as random effect, one without) were compared to determine whether there was an effect of Fish ID (i.e., individual variance) on the shoaling results. There was no significant difference between the two models (i.e., neither model was more appropriate than the other; $p=0.99$ ), suggesting there is as much variance within individual response as there is between individuals. Thus, it can be concluded that stimulus shoal species had the strongest effect on focal fish shoal choice, rather than individual variation. 


\section{2-3.2 Bonefish and Pilchard Stimulus Shoals}

Juvenile bonefish generally tended to spend a similar amount of time with both conspecifics and pilchard (Fig. 2-2b). Focal fish spent nearly the same amount of time shoaling with conspecifics, pilchard, and non-shoaling. It was common for focal fish to swim around the experimental arena to all of the arms several times (i.e., entering and exiting shoaling zones), often without making a discernible choice to shoal with either shoal for a substantial amount of time. When comparing focal fish shoaling tendencies between conspecifics or pilchard, there was no significant interaction between shoal species and shoal size $\left(X^{2}=2.8, \mathrm{p}=0.42\right)$, nor was there a significant effect of shoal species $\left(X^{2}=0.06, \mathrm{p}=0.8\right)$ or shoal size $\left(X^{2}=0.5, \mathrm{p}=0.9\right)$ on juvenile bonefish shoal choice (Fig. 2-2b). Similar to the (i) bonefish or mojarra trials, two LME models (one with Fish ID as random effect, one without) were compared to determine whether there was an effect of Fish ID (i.e., individual variance) on the shoaling results between bonefish or pilchard. There was no significant difference between the two models (i.e., neither model was more appropriate than the other; $p=0.99)$, suggesting there is as much variance within individual response as there is between individuals. Thus, it can be concluded that stimulus shoal species had the strongest effect on focal fish shoal choice, rather than individual variation.

\section{2-3.3 Bonefish and Mixed Stimulus Shoals}

When given the choice between bonefish or mixed shoals, focal fish preferred to spend more time shoaling with the mixed shoals of bonefish and mojarra than with the conspecific shoal (Fig. 2-3a); focal fish were engaged with a shoal nearly three quarters of the time, with $66 \%$ of that time spent shoaling with the mixed shoal. There was a significant difference between time spent shoaling with bonefish (mean $=263 \pm 63 \mathrm{~s} \mathrm{SE})$ and time spent shoaling with the 
mixed shoal (mean $=619 \pm 79 \mathrm{~s} \mathrm{SE})$. Focal fish spent significantly more time shoaling with the mixed shoal than with conspecifics $(t=-2.6, d f=24, p=0.02)$.

\section{2-3.4 Mojarra and Mixed Stimulus Shoals}

Contrary to the results of the bonefish or mixed shoal trials, focal fish preferred to shoal with the mojarra stimulus shoal, rather than spending their time with the mixed shoal (Fig. 2-3b); similarly focal fish spent nearly three quarters of their time engaged with a shoal, with $70 \%$ of that time spent shoaling with mojarra. There was a significant difference between the time focal fish spent shoaling with mojarra $($ mean $=581 \pm 62 \mathrm{~s} \mathrm{SE})$ and time spent shoaling with the mixed shoal (mean $=291 \pm 56 \mathrm{~s} \mathrm{SE}$ ). The focal fish in this trial spent significantly more time with mojarra than with the mixed shoal $(\mathrm{t}=2.8, \mathrm{df}=24, \mathrm{p}=0.01)$.

\section{2-4. Discussion}

The results of this study consistently suggest that juvenile bonefish prefer to actively shoal with mojarra rather than other species options afforded to them throughout the experiment. The four treatments in which focal fish were given a shoaling choice were: (i) bonefish or mojarra (four trials; $1 \times 1,2 \times 2,4 \times 4,8 \times 8$ ), (ii) bonefish or pilchard (four trials; $1 \times 1,2 \times 2,4 \times 4$, $8 \times 8$ ), (iii) four bonefish or a mixed shoal (two mojarra and two bonefish), and lastly (iv) four mojarra or a mixed shoal (two mojarra and two bonefish). For the (i) bonefish or mojarra treatment, in three of the four trials, juvenile bonefish showed a significant preference for shoaling with mojarra (Fig. 2-2a). Focal fish showed a strong preference for mojarra during the $1 \times 1,4 \times 4$, and $8 \times 8$ treatments, spending substantially more time with mojarra on average than with conspecifics. However, a disparity in my results is in the $2 \times 2$ treatment, where focal fish spent approximately the same amount of time with conspecifics and with mojarra, although mean 
time spent with mojarra was marginally higher. This result is in contrast to the overall trend of my results, and I surmise it may be largely due to a low sample size resulting in low statistical power; with more trials, it is likely the results would have followed the same trend as the other results. Another potential explanation for this disparity may be that there is an ecological implication (i.e., stimulus shoal individuals in the $2 \times 2$ were less social; group sizes of two are an unattractive shoal choice; e.g., Cote et al. 2012; Laskowski \& Bell 2014). During the treatment where focal fish were given the choice between (ii) conspecifics or pilchard, focal fish showed no preference for shoaling with either stimulus shoal (Fig. 2-2b). Instead, focal fish appeared to spend their time equally between the conspecific shoal, the pilchard shoal, and non-shoaling. The focal fish were often swimming around the experimental arena and between the stimulus shoals, without spending significant time with either. During both of the two mixed shoal treatments, focal fish had a strong tendency to shoal wherever there was the highest proportion of mojarra (Fig. 2-3). In the treatment where focal fish were given the opportunity to shoal with either (iii) four conspecifics or a mixed shoal, the focal fish tended to shoal with the mixed shoal that included two mojarra as well as two conspecifics (Fig. 2-3a). Lastly, when given the option to shoal with (iv) four mojarra or a mixed shoal, focal fish had strong tendencies to shoal with mojarra, abandoning their previous preference for the mixed shoal. Within the confines of my study, the results from the two mixed shoal treatments support the hypothesis that juvenile bonefish have a preference to shoal wherever there is the highest proportion of mojarra.

Anti-predator and foraging benefits are commonly attributed as the key advantages of grouping (Morse 1977; Krause \& Ruxton 2002; Sridhar et al. 2009). Anti-predator advantages exist in the context of attack abatement, predator confusion, and increased vigilance (Pitcher \& Parrish 1993; Turner \& Montgomery 2003). Another consideration in predator-prey models is 
the 'oddity effect', whereby phenotypically dissimilar fish are more easily and readily targeted by predators (Landeau \& Terborgh 1986). In the context of my study, the existence of the oddity effect would suggest that juvenile bonefish should prefer to shoal with conspecifics, or to a lesser extent, pilchard (more phenotypically similar than mojarra). Presumably, shoaling with either conspecifics or pilchard would lessen the oddity effect, thereby lowering predation risks for individuals (Landeau \& Terborgh 1986); however, this was not the case in my study. Not only did juvenile bonefish show no preference during the treatment with either pilchard or conspecifics, they also showed little preference for conspecifics throughout the entirety of the experiment. Therefore, my results suggest that the greatest benefits juvenile bonefish derive from shoaling with mojarra may not necessarily be related to anti-predator advantages, although antipredation as a mechanism deserves future research attention. Other possible mechanisms may be linked to similarities in foraging modes, microhabitat usage, and spatial niche overlap leading to closer associations between juvenile bonefish and mojarra.

Juvenile bonefish, mojarra, and pilchard all have substantial habitat overlap in tropical and subtropical nearshore habitats (Sogard et al. 1989). However, it can be speculated that the ways in which they are organized in these nearshore habitats differ, resulting in the utilization of different microhabitats. Juvenile bonefish and mojarra are benthivorous fish and belong to the same trophic classification (Reis-Filho et al. 2011), whereas pilchard are zooplanktivorous and remain higher in the water column (Modde \& Ross 1983). Therefore, I suggest juvenile bonefish and pilchard are unlikely to have strong associations with one another due to their different foraging modes, likely resulting in little spatial niche overlap. It is also worth noting that while pilchard are arguably more phenotypically similar to juvenile bonefish, mojarra still share superficial similarities with juvenile bonefish. Both mojarra and juvenile bonefish have similar 
dorsal and lateral pigmentation, and are difficult to distinguish in a mixed shoal. Additionally, due to their wide distribution and abundance in nearshore habitats, mojarra may also behave as important information centers for juvenile bonefish, relying on mojarra shoals to inform them of lucrative foraging opportunities (Seppänen et al. 2007).

Evidence of foraging modes and microhabitat usage suggests that mojarra may be an attractive shoal choice for juvenile bonefish. However, these attributes alone are not necessarily sufficient to explain bonefish shoaling preference for mojarra and not conspecifics. In addition to their spatial overlap, mojarra have also demonstrated an auditory specialization which may allow for superior prey-finding (Parmentier et al. 2011). Juvenile bonefish and mojarra may also limit resource competition through differences in the morphology of their feeding apparatuses (Zahorcsak et al. 2000; Snodgrass et al. 2008). Mojarra possess an auditory adaptation whereby their swim bladder has a specialized connection to the inner ear, and a modified cone in their pelvic fin where it sits, all acting to enhance the acoustic amplification provided by the swim bladder (Parmentier et al. 2011). It has been hypothesized that this specialized adaptation is not used for communication, but instead may be used to hear benthic invertebrate prey below the surface of the substrate (Braun \& Grande 2008; Parmentier et al. 2011). It may be speculated that this auditory specialization would be beneficial to bonefish foraging success, thereby making mojarra an advantageous shoal mate.

Mojarra may suffer from the associated cost of increased competition due to their auditory specialization if shoal mates are kleptoparasitic (e.g., Webster \& Hart 2006); however, their association with juvenile bonefish may not result in increased competition due to potential trophic resource partitioning. Using isotopic analysis, Haak (unpubl. data) determined that although juvenile bonefish and mojarra utilize similar habitats and are oftentimes caught 
together, they do not appear to have dietary overlap, and instead satisfy slightly different trophic niches. Resource niche partitioning is a common occurrence in both avian and fish communities, and has been strongly supported in the literature (e.g., Labropoulou \& Eleftheriou 1997; Radford \& Du Plessis 2003; Krajewski et al. 2006; Harrison \& Whitehouse 2011). Although this was neither explicitly examined in Haak (unpubl. data), nor in the current study, an explanation for the disparity in prey types may be due in part to the morphological differences in their feeding apparatuses (Vega-Cendejas et al. 1994). Mojarra have a protractable mouth that is able to extend and protrude into the substrate (Sazima 1986; Zahorcsak et al. 2000), whereas bonefish have a hard palette designed to grind the shells of invertebrates (Alexander 1961). Since bonefish only have a limited ability to protract their mouths and primarily rely on burrowing their snouts into the substrate to capture prey, they may consume prey closer to the surface of the substrate (Snodgrass et al. 2008; Brownscombe et al. 2014), thereby excluding them from mojarra prey types.

My results suggest that there are affiliative interactions between mojarra and bonefish, although the mechanisms are still unknown and require further research. This study was the first to explore the shoaling preferences of juvenile bonefish, and as such, the plausible drivers offered to support this preference are still speculative, but also open new avenues for future research. There are inherent difficulties associated with studying wild fish populations (Ostrander 2000); it is important to note that juvenile bonefish are present in low densities and are difficult to locate and capture, thus resulting in the current experimental design and limited sample size. Indeed, shoals of mojarra and juvenile bonefish in nature are substantially larger (often 10 s to even 100 s of individuals) than what was able to test experimentally. 
As my speculations about the mechanisms responsible for the multi-species shoaling preference have alluded to, there are several future directions of research to determine the behavioural and evolutionary drivers behind this association. Firstly, my contrasting results in the $2 \times 2$ bonefish and mojarra trial should be explored further to elucidate whether there is an ecological explanation, or whether it was caused merely by a small sample size and low statistical power. Future studies should possibly shift to become more 'mojarra-centric', rather than my current model. This shift would allow for further exploration of the notion that mojarra behave as a nuclear species (an observation of Haak, unpubl. data), thus driving the foraging activity of interspecific shoal mates (Lukoschek \& McCormick 2000). There is a body of evidence within the literature that suggests nuclear species may be more vigilant (e.g., Dolby $\&$ Grubb 1998; Ragusa-Netto 2002; Sazima et al. 2006), thereby providing their associate counterparts with the information to reduce predation, and thus their ecological uncertainty (Danchin et al. 2004; Dall et al. 2005). Additionally, future research exploring the possibility of mojarra incurring negative consequences from juvenile bonefish shoaling with them (i.e., kleptoparasitism, increased detection from predators, etc.) is an interesting future avenue to explore. Anecdotal evidence from the field has also suggested that juvenile bonefish may be a highly sought after prey species for nearshore predators, namely barracuda (Sphyraena barracuda) and mangrove snapper (Lutjanus griseus), when compared with mojarra. Experimental studies further examining this relationship could aim to determine whether juvenile bonefish also derive anti-predator benefits from shoaling in large multi-species shoals with mojarra (e.g., FitzGibbon 1990; Sridhar et al. 2009). In addition, further behaviour experiments could ascertain whether there is the occurrence of an 'oddity effect' resulting in juvenile bonefish being a preferred prey type, or whether their superficial similarities to mojarra can be attributed 
to this selective pressure (Landeau \& Terborgh 1986; Krause \& Ruxton 2002; Sazima 2002). The results of this study provide conjecture to explain the observed shoaling preference, but also acknowledge that more research is required to determine the underlying behavioural, ecological, and evolutionary mechanisms driving this relationship. 


\section{2-6. Figures}

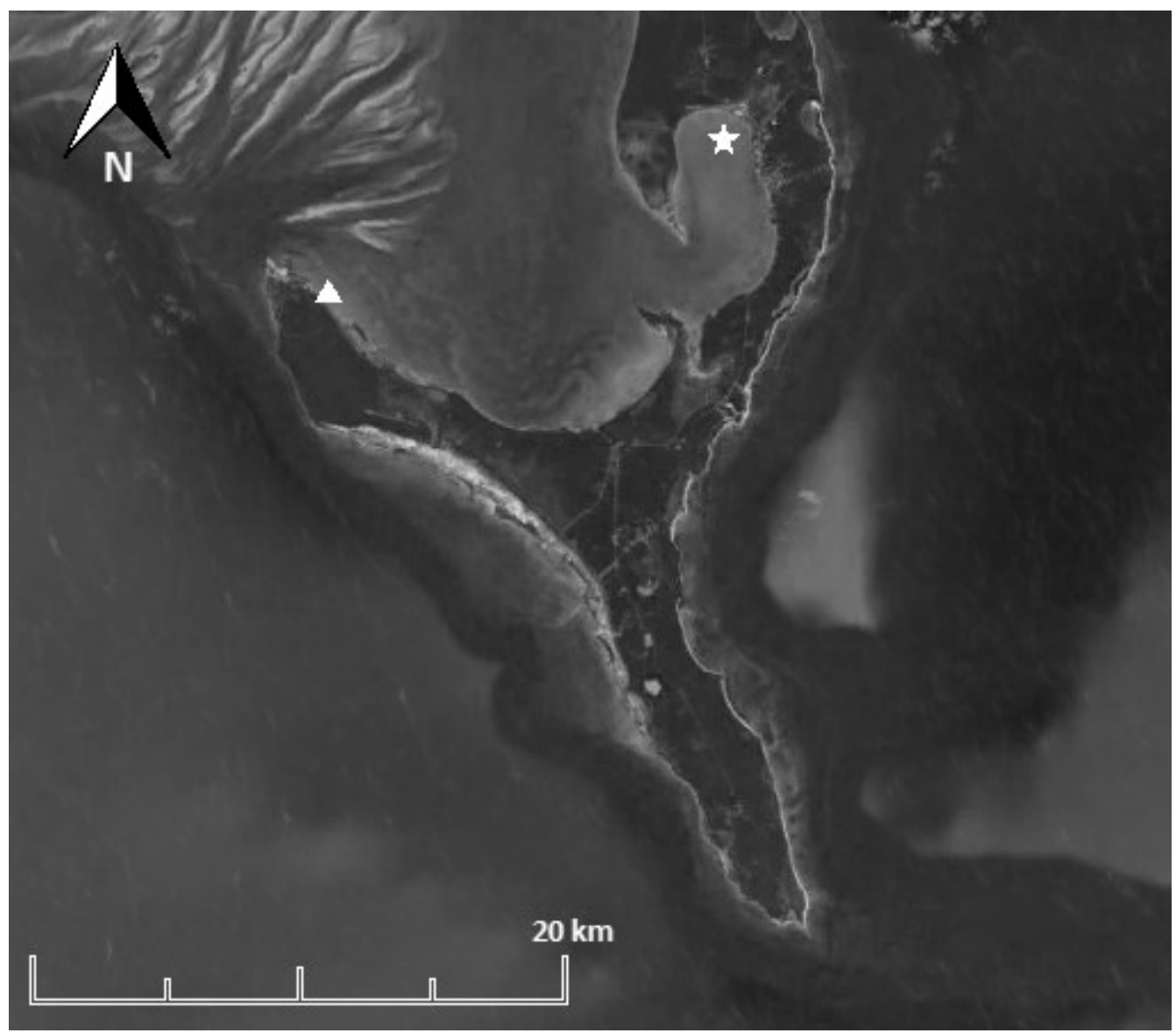

Fig. 2-1 A map of southern Eleuthera, The Bahamas (developed using Google Earth Pro). The star denotes the capture and collection site of juvenile bonefish in Rock Sound, and the triangle denotes the location of the Cape Eleuthera Institute wet lab. 

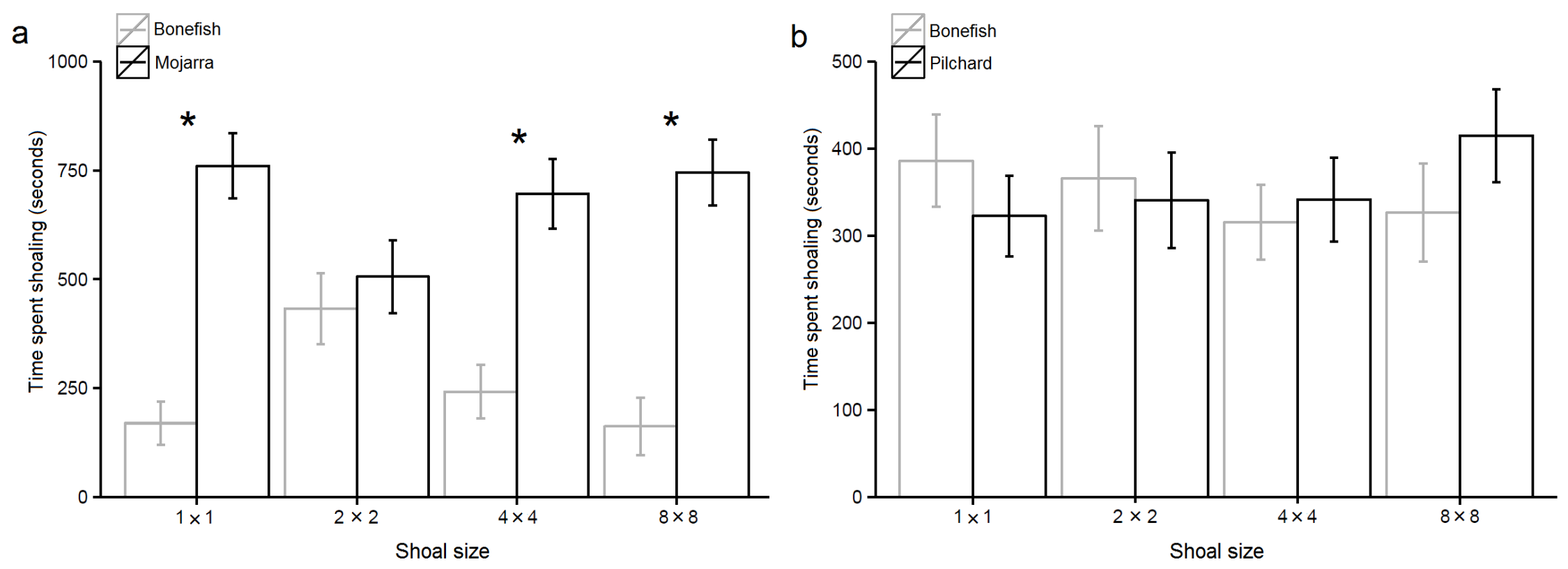

Fig. 2-2 Mean responses ( \pm SE) of time focal bonefish spent (in seconds) shoaling with other bonefish or mojarra (2-2a), and time spent (in seconds) shoaling with bonefish or pilchard ( $2-2 \mathrm{~b})$ in stimulus shoal sizes of $1 \times 1,2 \times 2,4 \times 4,8 \times 8$. Asterisks (*) denote significant differences between species in each shoal size. 

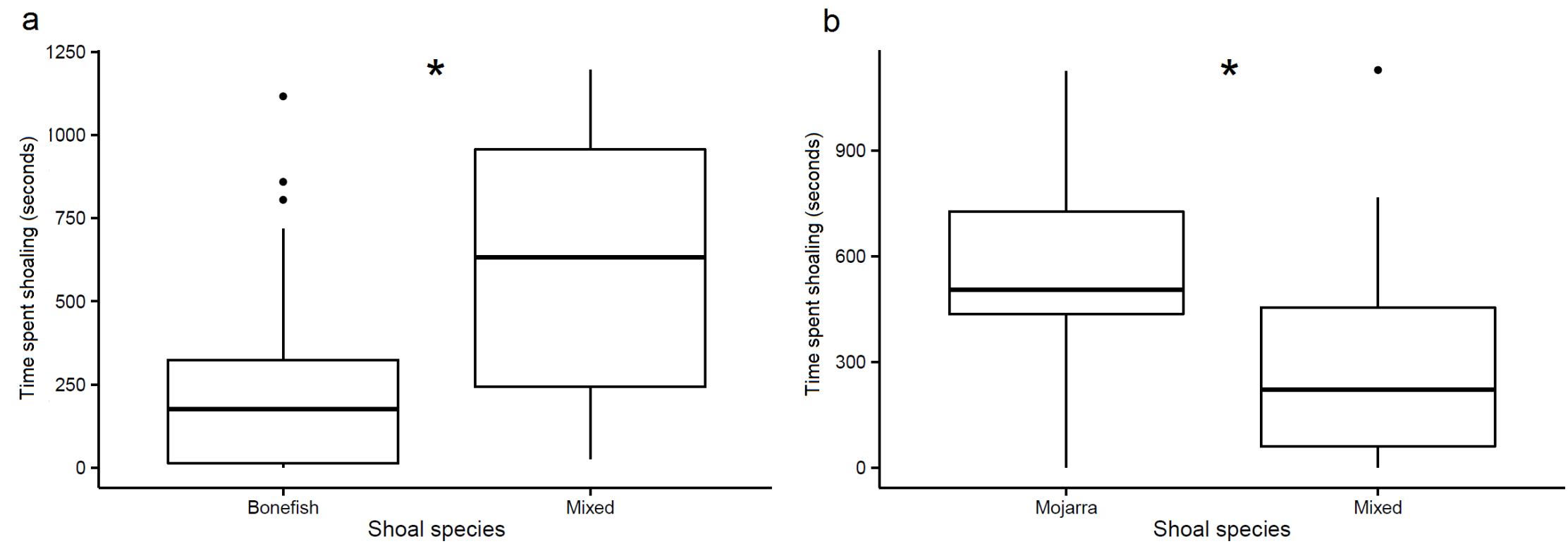

Fig. 2-3 Box-and-whisker plot of time focal bonefish spent (in seconds) shoaling with four bonefish or a mixed shoal of two bonefish and two mojarra (2-3a), and time focal bonefish spent (in seconds) shoaling with four mojarra or a mixed shoal of two bonefish and two mojarra(2-3b). The horizontal bold line within the box indicates the median of the data, while the boundaries of the box indicate the $25^{\text {th }}$ and $75^{\text {th }}$ percentiles, and the whiskers denote upper and lower data points outside the middle $50^{\text {th }}$ percentile. Asterisks $(*)$ denote significant differences between single species and mixed species shoals. 


\section{Chapter 3: Does Coastal Light Pollution Alter the Nocturnal Behaviour and Blood Physiology of Juvenile Bonefish (Albula vulpes)?}

\section{3-0. Abstract}

Light pollution is a prevalent but often overlooked ecological concern in a variety of ecosystems. Marine environments are subjected to artificial lighting from coastal development, in addition to offshore sources such as fishing vessels, oil platforms and cruise ships. Fish species that rely on nearshore habitats are most significantly impacted by coastal light pollution as they, particularly as juveniles, are often limited to nearshore habitats due to predation risk in deeper offshore waters. Juvenile bonefish rely on nearshore habitats, and are therefore exposed to coastal lighting and development. This study assessed juvenile bonefish behaviour and physiology in the presence of two common light sources: constant street lighting (high pressure sodium) and intermittent car headlights (H4 halogen). The behavioural responses were compared with a night and day control, whereas physiology was only compared with a night control. Each behavioural trial had two time periods: light and recovery (2 hr each). Physiology (blood glucose and whole body cortisol) was assessed after an overnight $8 \mathrm{hr}$ exposure. The results suggest that there is no effect of light pollution on the swimming behaviour or whole body cortisol of juvenile bonefish, but that both forms of light pollution resulted in elevated blood glucose concentrations relative to controls, with constant light glucose levels being significantly higher. Additional research is needed to understand the ecological consequences of light pollution on bonefish and other coastal marine fish using additional endpoints, assessing fish over longer time periods, and ideally combining data from the lab and the field. 


\section{3-1. Introduction}

In many respects, artificial lighting has been beneficial to humanity, particularly with regards to improving security and facilitating modern urban lifestyles (Jakle 2001; Doll et al. 2006). However, these benefits have come with a number of detrimental impacts to the natural world (Vitousek et al. 1997; Crutzen \& Stoermer 2000). Most, if not all, metazoan species occurring outside of the abyssal zones of the oceans have evolved in the presence of natural diel variation, with the availability of light in the form of solar radiation (Heldmaier 1989; Menaker et al. 1997; Panda et al. 2002, Kalsbeek et al. 2012). This variation forms the basis of neuroendocrine-based circadian rhythms that influence multiscale phenologies including metabolism, growth, and behaviour (Dunlap 1999; Dodd et al. 2005; Ko \& Takahashi 2006; Bass \& Takahashi 2010). While more insidious pollutants such as those arising from the combustion of various materials (i.e., coal, wood, or oil) have been on the scientific radar since the 1840s (Macfarlane et al. 1841), artificial lighting has only recently garnered the attention of the scientific community (Vinogradova et al. 2009). Ecological light pollution (described in Longcore \& Rich 2004) arises from the excessive and inefficient use of artificial lighting, a phenomenon that is increasing at a rate of approximately $6 \%$ annually on a global scale (Hölker et al. 2010). Consequences of ecological light pollution on animals have been measured across taxa and scales ranging from individuals to entire ecosystems, with disruptions in spatial orientation, foraging patterns, migration, reproduction, predation, and communication (all reviewed in Longcore \& Rich 2004). Despite this growing body of evidence, light remains an often-overlooked form of pollution (Rudd \& Lawton 2013).

While some research efforts have focused on terrestrial ecosystems, freshwater and marine environments have not garnered the same level of attention (Depledge 2010; Davies et al. 2014). Nearshore freshwater and marine species are exposed to artificial lighting due to coastal development, 
while some offshore species may be exposed to lighting on bridges, oil platforms, fishing vessels, and cruise ships (Hölker et al. 2010; Davies et al. 2014). Species relying on nearshore habitats get very little respite from lighting caused by coastal development, particularly in places like the southeastern coast of Florida where essentially all available shoreline has been developed (Finkl \& Charlier 2003). In addition, tropical and subtropical species may be more susceptible to alterations in ambient light, as these latitudes experience relatively little variation in diel light cycles throughout the year (Gliwicz 1999). Thus, light pollution along coastlines may leave juvenile life stages of fish vulnerable, as they cannot readily relocate, and may experience elevated predation risk if they attempt to leave their nearshore nurseries (Werner et al. 1983; Laegdsgaard \& Johnson 2001). Juvenile bonefish (Albula vulpes) are one such species that rely on nearshore habitats, and may be impacted by coastal lighting and development. In some regions of their range, adult bonefish populations are in decline and some populations (e.g., Florida) have been designated as 'near-threatened' under IUCN criteria (Adams et al. 2014). In addition, exhaustive efforts to locate juvenile bonefish along developed coastlines have been met with little success over the past two decades, especially in developed areas of Florida (Adams et al. 2008; Snodgrass et al. 2008), although they are readily found along less-developed shorelines in some regions of The Bahamas. Bonefish are a relatively long-lived species, with some adults having reached approximately 20 to 25 years of age (Larkin 2011; Haak, unpubl.data). Therefore, if there is a threat or a decline in the juvenile population, it may not be evident in the adult population for several decades.

The objective of this study was to determine the acute effects of ecologically relevant light pollution on juvenile bonefish behaviour and physiology. I examined juvenile bonefish behaviour when exposed to light pollution, and measured their blood glucose levels (a simple stress indicator; Barton 2002) post-exposure, and evaluated whole body cortisol. Wild-caught juvenile bonefish were exposed to two ecologically relevant light treatments: constant simulated street lighting (high pressure 
sodium) and intermittent car headlights (H4 halogen), and compared their responses to control animals. This work will provide insights into the potential effects of light pollution on the behaviour and physiology of juvenile bonefish and may act as a model for other fish species utilizing similar habitat.

\section{3-2. Methods}

\section{3-2.1 Capture and Transport}

The study was conducted in south Eleuthera, The Bahamas (N 2450'05" and W $\left.76^{\circ} 20^{\prime} 32^{\prime \prime}\right)$ at the Cape Eleuthera Institute (CEI) during April and August of 2015 (Fig. 2-1). A shallow nearshore area $(<1 \mathrm{~m}$ depth) was spot-seined $(15.25 \mathrm{~m}$ length $\times 1.22 \mathrm{~m}$ height, $0.6 \mathrm{~cm}$ mesh size $)$ for juvenile bonefish in Rock Sound (Fig. 2-1). Upon capture, juvenile bonefish were transferred from the seine to a flow-through net pen $(1.50 \mathrm{~m}$ length $\times 0.7 \mathrm{~m}$ width $\times 1.20 \mathrm{~m}$ height $)$ to keep fish in well oxygenated and ambient water while seining continued for more individuals. Fish were then transferred to large coolers $(90 \mathrm{~cm}$ length $\times 35 \mathrm{~cm}$ width $\times 20 \mathrm{~cm}$ height; $63 \mathrm{~L})$ on the boat for transportation, with a maximum density of 10 fish per cooler. Approximately 1/3 volume water changes occurred every 10 min over the course of the 30 min boat transport. Upon arrival at the CEI wet lab facility, fish were transferred to circular tanks $(155 \mathrm{~cm}$ diameter $\times 25 \mathrm{~cm}$ height; $472 \mathrm{~L})$ which were aerated and continuously supplied with fresh seawater $(10 \mathrm{~L} / \mathrm{min})$ at ambient water temperatures $\left(27.8 \pm 2.1^{\circ} \mathrm{C}\right.$ SD); densities never exceeded 20 fish per tank. Fish were collected using bonefish handling techniques (Murchie et al. 2009) but adapted for this more sensitive life stage (Laegdsgaard \& Johnson 2001). When a fish was transferred, it was gathered from the water in a container $(15 \mathrm{~cm}$ diameter $\times 20 \mathrm{~cm}$ height; $3.5 \mathrm{~L}$ ) and gently poured into the new area of containment (e.g., from net to cooler). This technique ensured the fish were never exposed to air (Cook et al. 2015) and minimized abrasion caused by nets and handling (Murchie et al. 2009). In April, 20 juvenile bonefish 
$($ mean $=109 \pm 6 \mathrm{~mm}$ SD fork length; 96-116 mm) were collected from Rock Sound for the behaviour portion of the study, and 30 juvenile bonefish (mean $=71 \pm 5 \mathrm{~mm} \mathrm{SD}$ fork length; 60-78 $\mathrm{mm}$ ) were collected from the same location in August for the physiology aspect of the study. Fish were given a minimum of $48 \mathrm{hr}$ to acclimate to laboratory conditions before experimentation.

\section{3-2.2 Behaviour Trials}

Each trial consisted of four treatments that took place over three days; the four treatments were (i) control day lighting; (ii) control night lighting; (iii) constant lighting from a high-pressure sodium bulb (Globe Electric; Montreal, Quebec, Canada; 150 watt bulb), which simulated nearshore street lighting; and (iv) intermittent lighting from a H4 halogen car light (Sylvania; Mississauga, Ontario, Canada; H4 bulb), which was meant to simulate passing cars in nearshore environments (light was on 1 min every 10 min using a timer). In this case, 'ambient' refers to natural illumination (i.e., night sky or daylight), through the semi-transparent roof. Each juvenile bonefish $(n=20)$ was used in each of the four treatment groups and experienced the treatments in a unique order, with four fish per trial.

Fish were moved from the circular holding tanks to the experimental raceways on the morning of the first day of trials at $08 \mathrm{~h} 00,14 \mathrm{hr}$ before experimentation. The experimental set-up included two raceways that were situated in parallel and each raceway was split into two sections yielding four arenas in total $(150 \mathrm{~cm}$ length $\times 62 \mathrm{~cm}$ width $\times 22 \mathrm{~cm}$ height; $205 \mathrm{~L}$; Fig. $3-1)$. Sections were separated by black partitions that allowed for water flow-through but did not allow fish to see other focal individuals. Each section of the experimental arena had lines on the bottom of the tank every $15 \mathrm{~cm}$ to measure the number of lines crossed as a proxy for horizontal distance traveled. The water leading into the raceways was aerated and pumped into a segmented end of the raceway $(6 \mathrm{~L} / \mathrm{min}$; $26.9 \pm 1.6^{\circ} \mathrm{C} \mathrm{SD}$ ) to ensure aeration did not disturb the water in the experimental arenas. The highpressure sodium and $\mathrm{H} 4$ halogen lights were mounted $3.5 \mathrm{~m}$ above the bottom of the raceways, 
directly above where the raceways were segmented to ensure no compartment had shadows during light exposure (Fig. 3-1). The illuminance (lux) was recorded using a lux meter (Dr. Meter ${ }^{\circledR}$, Hisgadget Inc., Union City, California, United States of America) for both high pressure sodium and H4 halogen light at the surface of the water (48 lux and 80 lux respectively) and in a nearshore area that had street and car lighting spill over (25 lux and 68 respectively). Ambient night conditions ranged from 0.02 to 1.6 lux. Raceways were located in an open-air wetlab, with a semi-transparent roof, which may have allowed for a small amount of moonlight. During the experiment, moon phase was between the last quarter and the first quarter $(<50 \%$ full), although many of the nights were overcast.

The light treatments (constant and intermittent) included two phases: first, fish were exposed to artificial light between $22 \mathrm{~h} 00-00 \mathrm{~h} 00$, and then a recovery period ran from $00 \mathrm{~h} 00-02 \mathrm{~h} 00$ where the fish were left in ambient darkness. The night and day controls were also assessed based on two time periods, without the influence of any artificial lighting. Fish were filmed (DVR9-42009 Channel 960H Digital Video Recorder and PRO-642 Cameras; Swann Communications U.S.A Inc.; Santa Fe Springs, California, United States of America) from 22h00-02h00 for the night controls, constant lighting and intermittent lighting treatments, and 10h00-14h00 for the day controls. While not being filmed, fish were left in a natural photoperiod with ambient night- or day- sky, as the semi-transparent roof would allow. Fish were fed small shrimp fragments ad libitum at $08 \mathrm{~h} 00$ each morning. After the four fish from the first trial were subjected to each of the four treatments, they were removed and put in a new holding tank, and another four fish were distributed as described above.

\section{3-2.3 Video Analysis}

Following the experiment, the videos for each fish were analyzed using JWatcher (Blumstein \& Daniel 2007). Videos were analyzed in 10 min segments for each hr of filming. Distance traveled 
was conservatively estimated using lines crossed as a proxy. Three behaviours were considered: number of $90^{\circ}$ turns, number of freeze events $(>1 \mathrm{sec})$, and number of burst events (sudden, rapid, undirected swimming). These parameters were assessed to determine whether there was evidence for unusual or erratic swimming behaviour during either of the light treatments when compared with control or recovery periods.

\section{3-2.4 Physiology}

Juvenile bonefish $(\mathrm{n}=10$ /treatment $)$ were moved from their holding tanks $(1.55 \mathrm{~m}$ diameter $\times$ $0.25 \mathrm{~cm}$ height; $472 \mathrm{~L})$ into segmented net pens in the experimental tank $(35 \mathrm{~cm}$ length $\times 30 \mathrm{~cm}$ width $\times 20 \mathrm{~cm}$ height; $21 \mathrm{~L} ; 0.3 \mathrm{~cm}$ fine mesh) at $16 \mathrm{~h} 00$ and left to rest. At 20h00, ten fish were subjected to one of three treatments: (i) control ambient night conditions; (ii) constant high-pressure sodium lighting; and (iii) intermittent $\mathrm{H} 4$ halogen lighting ( 1 min on $10 \mathrm{~min}$ off). Fish were kept in groups of three in the net pens to ensure that all fish were not alerted as they were dip netted for lethal sampling the following morning. The fish were left in their treatment until $04 \mathrm{~h} 00$, at which point they were netted out three at a time and euthanized using cerebral percussion and immediately $(<3$ min; Clark et al. 2011) had blood taken from their caudal vasculature to assess blood glucose concentrations (mmol/L) using a previously validated point-of-care device (ACCU-CHEK glucose meter; Roche Diagnostics; Basel, Switzerland; Stoot et al. 2014).

To measure total body cortisol (ng/g), whole body samples were frozen at $-20^{\circ} \mathrm{C}$ during transportation before being relocated to $-80^{\circ} \mathrm{C}$ for short term storage. Whole body samples were individually ground over liquid nitrogen with a chilled mortar and pestle. Ground samples were weighed and homogenized with $400 \mu \mathrm{L}$ of homogenizing buffer $\left(80 \mathrm{mM} \mathrm{NA}_{2} \mathrm{PO}_{4}, 20 \mathrm{mM} \mathrm{NaH}_{2} \mathrm{PO}_{4}\right.$, $100 \mathrm{mM} \mathrm{NaCl}$ and 1mM EDTA) using a hand-held homogenizer (Pellet Pestle Motor, Kimble ${ }^{\circledR}$ Kontes, Vineland, New Jersey, United States of America). The samples were then treated with $600 \mu \mathrm{L}$ 
of methanol, vortexed and incubated at $4{ }^{\circ} \mathrm{C}$ in the dark for $60 \mathrm{~min}$. They were then centrifuged for $5 \mathrm{~min}$ at $4{ }^{\circ} \mathrm{C}(3,000 \mathrm{~g})$ and flash frozen for $10 \mathrm{~min}$ at $-80^{\circ} \mathrm{C}$. The supernatant was pipetted into new tubes, and dried with an air stream until only a pellet remained. This process was repeated twice more. The samples were reconstituted in $900 \mu \mathrm{L}$ of extraction buffer and assayed using a cortisol ELISA kit (\#402710, Neogen Corporation, Lansing, Michigan, United States of America) to yield whole body cortisol.

\section{3-2.5 Statistical Analysis}

Each of the four behavioural measures failed to meet the assumptions of normality (ShapiroWilk test, all $\mathrm{p}<0.05$ ) so the data were rank-transformed and examined with ANOVA (Scheirer et al. 1976). Each behavioural measure was examined independently in a series of two-way repeated measures ANOVAs with time period (light, recovery) and treatment (four levels, described above) as main factors with an interaction term and individual fish as the repeated measure in 'aov' models. Any behavioural measure found to vary significantly with a main factor had the repeated measure term removed from the model for post-hoc analysis using Holm-corrected Tukey’s HSD tests. Variance component analysis was conducted to determine how much of the response was due to individual variation and how much was due to treatment effects. All analyses and figures were generated using $\mathrm{R}$ version 3.2.3 (R Core Team 2015) and the packages 'nlme' (Pinheiro et al. 2015), 'ape' (Paradis et al. 2004), 'varComp' (Qu 2015), and 'gplots' (Warnes et al. 2015). Statistical analysis was conducted on 16 of the 20 individuals in the experiment.

Measurements of blood glucose concentrations also did not meet the assumptions of normality (Shapiro-Wilk test, $\mathrm{p}<0.05$ ), in addition to having a small sample size per treatment. Therefore, a non-parametric Kruskal-Wallis test was used to examine the data, with a Nemenyi test post hoc test. 
Although whole body cortisol met the assumptions of normality, a Kruskal-Wallis test was used to account for the small sample size.

\section{3-3. Results}

\section{3-3.1 Behaviour}

The juvenile bonefish frequently exhibited all analyzed parameters. Juvenile bonefish swimming was a mix of non-directional, random swimming, as well as swimming the perimeter of the arenas; however, neither behaviour occurred substantially more than the other. Though not significant, juvenile bonefish appeared to demonstrate slightly lower levels of activity during recovery periods compared to light treatment periods (Fig. 3-2a, 3-2c, 3-2d), although this was not the case in the number of $90^{\circ}$ turns (Fig. 3-2 b). There were no significant effects of treatment, time period or individual as a repeated measure on either the distance traveled (Fig. 3-2a) or number of $90^{\circ}$ turns (Fig. 3-2b) in the repeated measures ANOVAs (all $\mathrm{p}>0.05$; Table 3-1). Variance component analysis indicated that for distance traveled and number of $90^{\circ}$ turns, individual variability was an approximately equal contributor to treatment effects (53.9\% and 46.4\%, respectively; Table 3-2).

For the number of freeze events, both the day and night controls froze more frequently than fish in either the constant or intermittent treatments (Fig. 3-2c). In all four treatments, fish froze more during the light than recovery periods. The two-way repeated measures ANOVA showed that there was no significant treatment effect; however, there was a significant effect of time period (light vs recovery; $\mathrm{p}<0.05$; Table $3-1$ ). The freeze responses of individuals did not vary significantly between treatment or time periods (Table 3-1). Variance component analysis showed individual variability accounted for $37.8 \%$ of the variation in freeze responses and the treatment effect accounted for $62.2 \%$, suggesting the treatments had slightly more influence on the behaviour (Table 3-2). 
The analysis for the burst events showed similar results to the freeze events. The number of burst events decreased for all treatments from the light to the recovery periods (Fig. 3-2d). Treatment did not have a significant effect on burst events, whereas time period did $(\mathrm{p}<0.001$; Table $3-1)$. In addition, there was a significant effect of time period within individuals ( $\mathrm{p}<0.05$; Table $3-1)$. Individual variability was responsible for $12.1 \%$ of the variation in burst responses, while treatment contributed $87.9 \%$ (Table 3-2), indicating that treatment had a much greater effect on this behavioural measure.

\section{3-3.2 Physiology}

Blood glucose concentrations ( $\mathrm{mmol} / \mathrm{L})$ varied significantly between treatments (KruskalWallis test; $\left.\mathrm{X}_{(2)}=7.5, \mathrm{p}=0.02\right)$. Mean concentrations increased with increasing levels of light exposure during nighttime $($ control $=3.83 \pm 1.12 \mathrm{mmol} / \mathrm{L} \mathrm{SD}$; intermittent $=4.36 \pm 0.96 \mathrm{mmol} / \mathrm{L} \mathrm{SD}$; constant $=5.12 \pm 0.80 \mathrm{mmol} / \mathrm{L} \mathrm{SD}$; Fig. 3-3). Based on the Nemenyi post hoc test, glucose concentrations of fish in constant lighting were significantly different from those in the control group $(\mathrm{p}=0.03)$, but not when compared against intermittent light $(\mathrm{p}=0.8)$. The intermittent fish were nearly significantly different from the controls, but missed the $95 \%$ confidence interval $(p=0.08)$. Whole body cortisol (ng/g) did not vary significantly between treatments $\left(\mathrm{X}_{(2)}=3.6, \mathrm{p}=0.16\right.$; control $=0.86 \pm 0.3 \mathrm{ng} / \mathrm{g} \mathrm{SE}$; intermittent $=0.87 \pm 0.3 \mathrm{ng} / \mathrm{g} \mathrm{SE} ;$ constant $=0.8 \pm 0.3 \mathrm{ng} / \mathrm{g} \mathrm{SD})$.

\section{3-4. Discussion}

This study assessed the effect of artificial lighting on juvenile bonefish swimming behaviour and physiology. Contrary to my predictions, there was no significant effect of light pollution on juvenile bonefish swimming behaviour. Blood glucose, a common indicator of stress in fish (Barton 2002), was measured following an overnight $8 \mathrm{hr}$ exposure to the two light treatments and compared with a night control. Following light exposure, blood glucose levels became elevated with increasing 
levels of light, with the constant treatment having significantly higher blood glucose concentrations than the control group which was not exposed to any artificial lighting. Despite glucose being elevated, cortisol levels post light exposure were not significantly different from the controls, a common result from photoperiod manipulation studies on fish (Brüning et al. 2015; Biwas et al. 2006, 2008). To my knowledge, this study is the first to specifically address the concern of nearshore artificial lighting on juvenile marine fish, and will add to the growing body of literature on the effects of artificial lighting on the natural world.

While my behavioural measurements did not yield any significant results from the light treatments themselves, there was an interesting trend in the number of freeze and burst events (Fig. $3-2 \mathrm{c}$ and $3-2 \mathrm{~d}$ respectively) for all four groups, where there was a decrease in locomotor activity between the light period and the recovery period. As there is no evidence of this response being related to experimental design (i.e., no disturbances during the recovery period), this trend suggests there may be a time effect, where fish are more active (i.e., alternating between bursting and freezing) during the earlier observed hours, and become less active during the latter part of the experiment. Another intriguing, though non-significant result, is the amount of bursting that fish in the intermittent treatment did relative to the other groups, particularly during the recovery period (Fig. 3-2d). I surmise that fish in the intermittent treatment burst more frequently, and continued to burst well into their recovery period due to experiencing more startling events with the light intermittently turning on and off during the light period.

Physiological stress is an adaptive mechanism by which fish are able to compensate or prepare for perceived or realized external stressors (Barton 2002). As such, an increase in blood glucose concentration is considered an adaptive secondary stress response (see Barton \& Iwama 1991). Following the overnight exposure to simulated constant street lighting and intermittent car headlights, 
juvenile bonefish experienced elevated blood glucose concentrations, with constant street lighting eliciting a significant difference from the control group. Furthermore, the extent to which they experienced elevated blood glucose appeared to be related to the duration of light exposure, with fish under constant lighting experiencing higher levels than those under intermittent lighting. Although this is the first study to quantify juvenile bonefish blood glucose, the results can be compared with adult bonefish blood glucose responses to various stressors. Light pollution is considered a perceived stressor, whereas catch-and-release angling acts as a physical stressor, and a cold shock event could behave as a chemical stressor (see Barton 2002 for definitions). Brownscombe et al. (2015) evaluated the physiological stress associated with catch-and-release angling of bonefish, and considered blood glucose concentrations as an indicator of angling stress. They found that an $\mathrm{hr}$ after an angling event ranging in duration from 70 to $245 \mathrm{~s}$, adult bonefish blood glucose concentration was measured at $5.2 \mathrm{mmol} / \mathrm{L}$; this value closely resembles the concentrations my study found following an $8 \mathrm{hr}$ exposure to constant street lighting $(5.12 \mathrm{mmol} / \mathrm{L})$. In another study conducted by Szekeres et al. (2014), adult bonefish were exposed to a $2 \mathrm{hr}$ cold shock event with water temperatures $7{ }^{\circ} \mathrm{C}$ and $14{ }^{\circ} \mathrm{C}$ below ambient conditions $\left(\sim 25^{\circ} \mathrm{C}\right)$ and noted values of $\sim 4.2 \mathrm{mmol} / \mathrm{L}$ post treatment, similar to my intermittent results $(4.36 \mathrm{mmol} / \mathrm{L})$; however, these values were not significantly different from controls in either study. In general, the elevation in glucose associated with constant light pollution for juvenile bonefish appears to be similar to that arising from catch-and-release angling of adults. Although glucose levels have been shown to be highest 1-2 hr post stressor, glucose levels often remain higher than controls even up to $24 \mathrm{hr}$ post stressor (Rotllant \& Tort 1997; Vijayan et al. 1997). I was unable to study longer-term glucose dynamics in this study.

The fact that cortisol concentrations were not significantly different among groups yet glucose was elevated in light treatments may suggest that there was a cortisol response but it was transient. Cortisol can become elevated rapidly after a stressor (i.e., minutes), and even after an intense acute 
stressor such as exercise is often returned to baseline levels within $4 \mathrm{hr}$ (Barton 2002) while glucose remains elevated for longer periods (Mommsen et al. 1999; Barton 2002). Given that cortisol mobilizes glucose reserves (Mommsen et al. 1999), it is not unreasonable to assume that a cortisol response occurred in the two light treatments but was not statistically discernable some $8 \mathrm{hr}$ after the initial light exposure (Pickering et al. 1982). It is also worth noting that due to low levels of cortisol during this experiment, juvenile bonefish likely experienced very little stress during holding or experimentation. Future studies should consider sampling fish at other intervals (e.g., $30 \mathrm{~min}, 1 \mathrm{hr}$, $2 \mathrm{hr}$ ) post treatment. I was unable to do so given limitations with the number of fish available (juvenile bonefish are difficult to capture in the wild) and the fact that only lethal sampling was possible given the small size of the fish.

Although artificial lighting has been an overlooked form of pollution for the last century, the evidence of negative consequences has been accumulating rapidly, with impacts to human health and natural ecosystems (Navara \& Nelson 2007). The overnight artificial light treatments of this study resulted in a secondary physiological stress response in the form of elevated glucose (Barton \& Iwama 1991). The behavioural parameters assessed did not yield significant results, which may be due to several reasons. Firstly, for a conservative estimate of distance travelled, only horizontal distance travelled was considered, whereas including vertical distance would have given a more representative indication of total distance traveled. Most notably, there may not have been a long enough light exposure period to elicit a behavioural response. As nearshore light pollution is not a "one-off" occasion and occurs every night, longer periods of light exposure over several nights may have been needed to trigger a behavioural response. Furthermore, I suspect there may have been a dilution effect with the intermittent treatment, as the light was only on for one minute out of ten. Due to the frequency and nature of passing cars, this is an important factor to consider; if fish are acutely startled by the light emitted by a passing car, there is the possibility of alerting nearby predators as a result of 
the erratic swimming behaviour. I concede that having a more frequent intermittent light may have been more indicative of passing cars in nearshore roadways; however, due to equipment and time restrictions I was required to use the current experimental design. Primary and secondary stress responses in fish often result in a tertiary response over time (Barton 2002). Thus, I speculate that if an overnight exposure to artificial light triggered a secondary response in the form of elevated blood glucose, that over many nights this effect may elicit a behavioural one as well. Indeed, there have been several studies where changes in physiological parameters do not always yield changes in fish behaviour (Cull et al. 2015; Pleizier et al. 2015). Disturbances to the natural light:dark cycle have provoked several tertiary responses across various taxa, and may result in changes to growth, reproductive timing, metabolism, habitat usage, feeding and foraging, and predation or predator avoidance (Dunlap 1999; also reviewed in Longcore \& Rich 2004 and Navara \& Nelson 2007).

It is important to note that juvenile bonefish are difficult to capture at this life stage; thus, it is possible that some of the trends would result in significance with a larger sample size. However, this study is still valuable as it represents the first attempt to study juvenile bonefish, and in a broader context, yields insight into the possible effects of artificial lighting on nearshore juvenile fish. I did not find any statistical support for behavioural consequences of light pollution with the behavioural metrics tested. As juvenile bonefish and other nearshore fishes are subject to a variety of natural lighting phenomenon (i.e., storms, lunar cycles, etc.), it is a possible explanation for why the acute light experiments did not elicit dramatic changes to behaviour. However, the results did determine that blood glucose levels became elevated with increasing exposure to artificial lighting. As chronic light exposure is more indicative of what nearshore juvenile bonefish experience, I propose a study looking at long-term effects could address whether the secondary responses would eventually result in tertiary responses (e.g., in behaviour). Future research should examine whether juvenile bonefish are attracted to- or repulsed by- artificial lighting, and if their foraging behaviour is altered, which may have 
implications for growth, as well as predation risk. Additionally, a study examining the response of phototactic bonefish leptocephali to artificial lighting, with regards to habitat choice and predation, could inform on disturbances to leptocephali recruitment. As an extension, future research should also consider predation with respect to juvenile or prey fish, by determining how their predators utilize and possibly optimize artificial lighting to hunt. My results provide a framework for future research to pursue the consequences of light pollution on nearshore fish. Further research on the effects of light pollution on juvenile bonefish should consider using an ecosystem approach and determining predation risk which might be mediated by light pollution. 


\section{3-6. Figures and Tables}

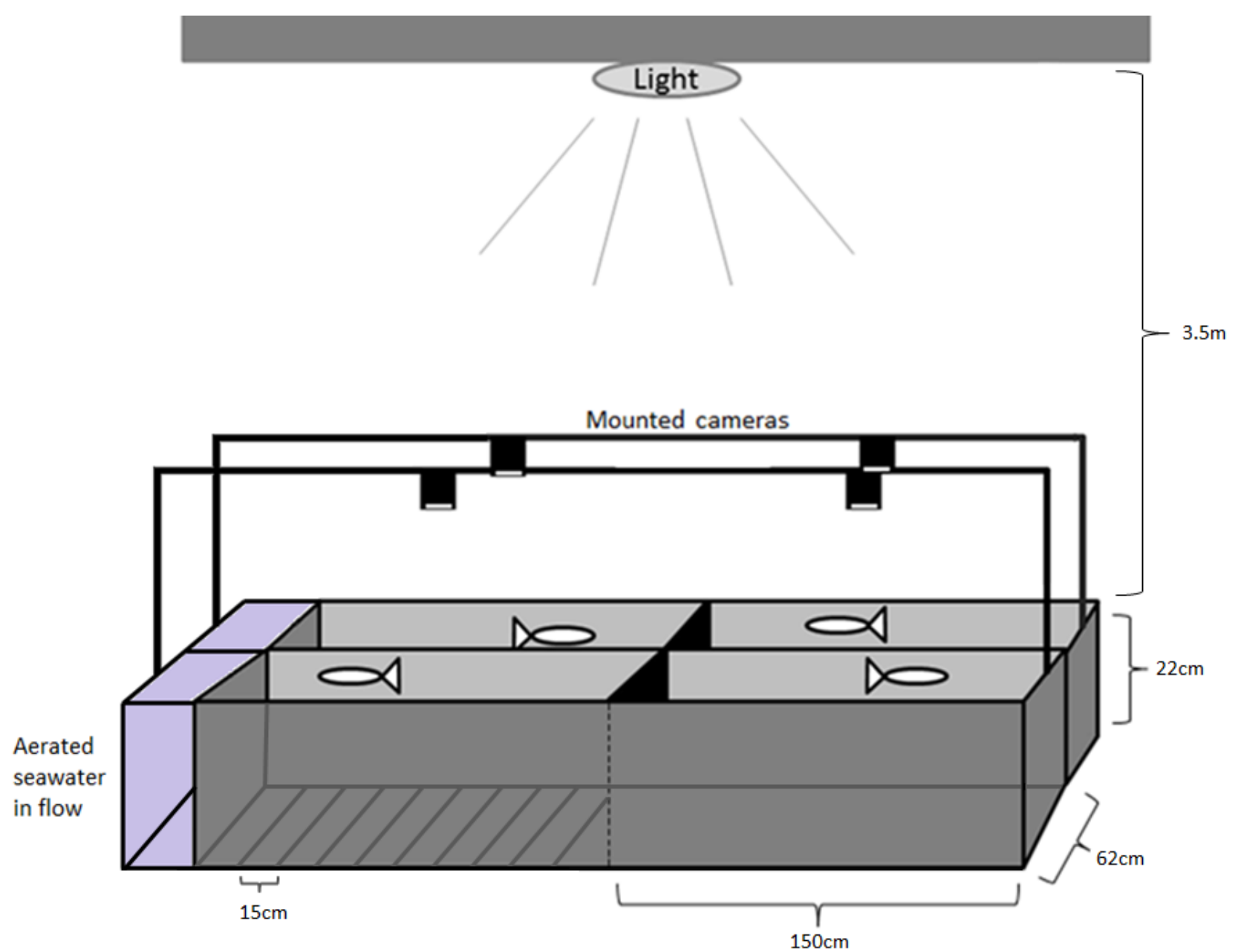

Fig. 3-1 Diagram of the experimental set up to assess the behavioural response of juvenile bonefish to experimental lighting conditions (i.e., constant and intermittent lighting). Cameras were mounted above each individual arena, and each arena was further subdivided on the bottom of the tank with lines to measure horizontal distance traveled. 

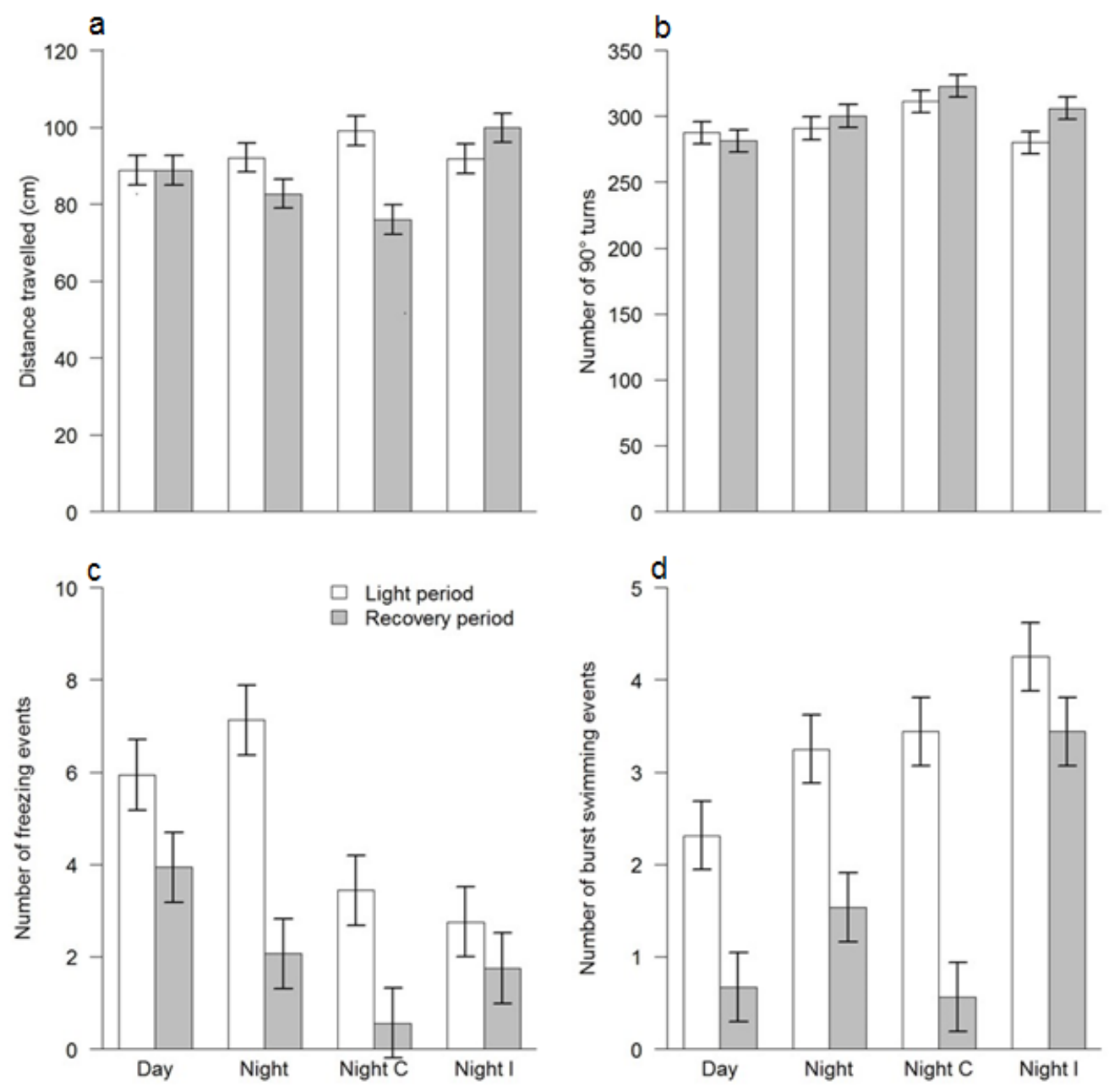

Fig. 3-2 Mean responses $( \pm \mathrm{SE})$ in (a) distance traveled (cm), (b) $90^{\circ}$ turns, (c) freeze events and (d) burst events demonstrated by juvenile bonefish (Albula vulpes) during two hr light treatment periods (open bars) and two hr ambient/dark recovery periods (shaded bars). Light periods consisted of a daytime control (Day), nighttime control (Night), constant light at night (Night C) and intermittent light at night (Night I). 


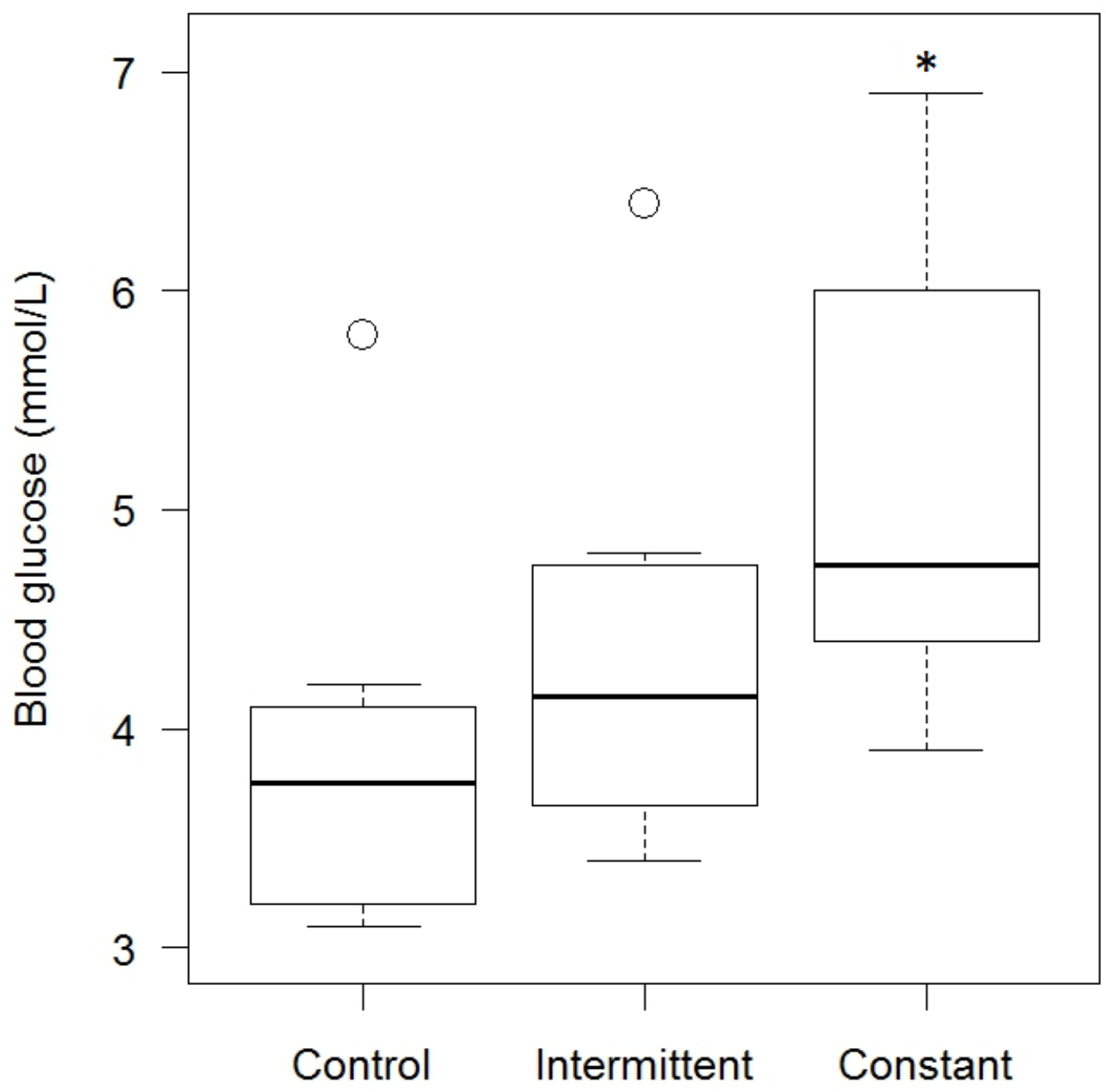

Fig.3-3 Boxplots illustrating median, $25^{\text {th }}$ and $75^{\text {th }}$ quartiles, and $95 \%$ CI blood glucose concentrations (mmol/L) in wild-caught, captive juvenile bonefish (Albula vulpes) immediately following exposure to constant, intermittent (1 min of constant light every $10 \mathrm{~min}$ ), or no artificial light (control) treatments between $20 \mathrm{~h} 00-04 \mathrm{~h} 00$. Asterisk $\left(^{*}\right)$ denotes significant pairwise differences between treatments from the Kruskal-Wallis test with Nemenyi test post hoc $(\mathrm{p}<0.05)$. 
Table 3-1 Repeated measures two-way analysis of variance in four behavioural responses in juvenile bonefish (Albula vulpes) during or after (Time) exposure to constant, intermittent light and a dark control at night and a daytime ambient light control (Treatment). Bold values indicate statistical significance $(\mathrm{p}<0.05)$.

\begin{tabular}{|c|c|c|c|c|c|c|c|c|c|c|c|c|c|c|c|}
\hline \multirow{3}{*}{ Behaviours } & \multicolumn{9}{|c|}{ Main effects } & \multicolumn{6}{|c|}{ Repeated measure (fish ID) } \\
\hline & \multicolumn{3}{|c|}{ Time } & \multicolumn{3}{|c|}{ Treatment } & \multicolumn{3}{|c|}{ Time*Treatment } & \multicolumn{3}{|c|}{ Time } & \multicolumn{3}{|c|}{ Treatment } \\
\hline & $\mathrm{F}$ & $\mathrm{df}$ & $\mathrm{p}$ & $\mathrm{F}$ & $\mathrm{df}$ & $\mathrm{p}$ & $\mathrm{F}$ & $\mathrm{df}$ & $\mathrm{p}$ & $\mathrm{F}$ & $\mathrm{df}$ & $\mathrm{p}$ & $\mathrm{F}$ & $\mathrm{df}$ & $\mathrm{p}$ \\
\hline Distance $(\mathrm{cm})$ & 1.88 & 1,103 & 0.174 & 1.40 & 3,103 & 0.246 & 1.20 & 3,103 & 0.314 & 0.58 & 1,13 & 0.458 & 0.50 & 1,13 & 0.492 \\
\hline Turns (\#) & 0.07 & 1,13 & 0.799 & 1.13 & 3,103 & 0.342 & 0.88 & 3,103 & 0.454 & 0.47 & 1,13 & 0.506 & 1.85 & 1,13 & 0.197 \\
\hline Freeze (\#) & 1.62 & 1,103 & 0.0098 & 1.89 & 3,103 & 0.136 & 1.62 & 3,103 & 0.188 & 2.79 & 1,13 & 0.119 & 0.18 & 1,13 & 0.675 \\
\hline Burst swim (\#) & 12.49 & 1,13 & $<0.001$ & 1.17 & 3,103 & 0.323 & 1.57 & 3,103 & 0.201 & 14.34 & 1,13 & 0.0023 & 1.45 & 1,13 & 0.250 \\
\hline
\end{tabular}


Table 3-2 Variance component analysis expressing the relative contributions (percent) of individual variability and treatment effects on observed behavioural responses of juvenile bonefish (Albula vulpes) exposed to constant, intermittent and no light at night and a daytime ambient light control.

\begin{tabular}{ccc}
\hline Behaviours & \multicolumn{2}{c}{ Variance Components } \\
& Individual & Treatments \\
\hline Distance (cm) & $53.9 \%$ & $46.1 \%$ \\
Turns (\#) & $46.4 \%$ & $52.6 \%$ \\
Freeze (\#) & $37.8 \%$ & $62.2 \%$ \\
Burst swim (\#) & $12.1 \%$ & $87.9 \%$ \\
\hline
\end{tabular}




\section{Chapter 4: General Discussion}

My thesis sought to understand juvenile bonefish behaviour and physiology to improve basic ecological understanding and inform how nearshore anthropogenic disturbances affect juvenile bonefish. In Chapter 2, the shoaling behaviour of juvenile bonefish was assessed as time spent shoaling with (i) conspecifics or mojarra, and (ii) conspecifics or pilchard of different shoal sizes $(1 \times 1,2 \times 2,4 \times 4,8 \times 8)$. In addition, juvenile bonefish shoaling preference was further examined when given a mixed shoal (two bonefish, two mojarra) as an alternative choice to either (iii) four bonefish, or (iv) four mojarra. Chapter 3 focused on the potential anthropogenic disturbance of light pollution on the behaviour and physiology of juvenile bonefish. During the behavioural component, juvenile bonefish were subjected to two forms of acute $(2 \mathrm{hr})$ artificial light pollution: constant street lighting (high pressure sodium), and intermittent car headlights (H4 halogen), and had swimming behaviours compared against night and daylight control values. For the physiological component, juvenile bonefish were subjected to either constant street lighting, intermittent headlights, or no artificial light. Following an overnight exposure $(8 \mathrm{hr})$, blood glucose and whole body cortisol were assessed.

Research on juvenile bonefish is in its early stages, with the work pre-dating my thesis being primarily observational. My thesis generated data from a controlled laboratory environment and produced foundational work that can be considered for future field-based studies. It is worth noting that lab-based behavioural trials have inherent limitations when attempting to apply results to wild animals (although laboratory studies fish shoaling choice are often considered consistent with fish shoaling in the wild; Krause et al. 2000). However, this research adds an integral aspect of juvenile bonefish behaviour that has not been previously studied. Additionally, juvenile bonefish are difficult to capture, resulting in very low catch per unit effort during collection. As a result, researching them in a controlled environment to begin with was the preferred approach. I submit that although I encourage future studies on juvenile bonefish to incorporate field components, using lab-based 
approaches were appropriate here given our prior limited understanding of juvenile bonefish behaviour and response to human intervention and experimentation.

\section{4-1.1: Findings and Implications}

In Chapter 2, I studied the shoaling preferences of juvenile bonefish; specifically, I aimed to determine whether the field observation of juvenile bonefish mostly being caught among larger quantities of mojarra was due to the relative abundance of mojarra (i.e., chance), or whether juvenile bonefish were actively integrating into a multi-species shoal (i.e., choice). My overall findings strongly suggest that juvenile bonefish actively shoal with mojarra when given the opportunity, and when mojarra are found in the highest proportion, as was the case for the results from the mixed shoal studies. During the (i) bonefish or mojarra treatment, focal fish spent significantly more time with the mojarra shoals in three of the four shoal size replicates. I suggest the lack of a significant difference during the $2 \times 2$ shoal size is likely due to having a low sample size, as the trend of spending more time with mojarra than conspecifics on average still exists; another explanation may be due to differences in sociality of stimulus fish used. The (ii) bonefish or pilchard treatment had contrasting findings, whereby the focal fish showed no real preference for shoaling with either stimulus shoal. Within the confines of this study, these findings suggest that predator avoidance and reducing the 'oddity effect' (Landeau \& Terborgh 1986) may not be a selective force for juvenile bonefish shoaling. If juvenile bonefish did shoal for the associated benefits of predator avoidance, a prediction may be that juvenile bonefish would prefer to shoal with fish that are phenotypically similar (i.e., conspecifics, or pilchard to a lesser extent). The findings of the (iii) bonefish or mixed shoal, and (iv) mojarra or mixed shoal studies lend themselves further to the notion of juvenile bonefish choosing to shoal with mojarra. When given the choice between conspecifics or a mixed shoal, focal fish spent significantly more time with the mixed shoal, whereas when the choices were mojarra or a mixed shoal, focal fish spent significantly more time with the mojarra shoal. Due to juvenile bonefish having no preference for 
phenotypically similar nearshore fishes, I offer some conjecture on the foraging benefits juvenile bonefish may acquire by shoaling with mojarra; however, additional research is still required to determine the underlying mechanisms of this relationship. Exploring the basic ecology of juvenile bonefish and the associations they have with other nearshore fish species is crucial to begin understanding their habitat and shoal mate requirements. Establishing the shoaling associations of juvenile bonefish may offer clues for understanding habitat or fish community assessments (i.e., absence of mojarra may be an indication of the absence of juvenile bonefish).

In Chapter 3, I explored the behavioural and physiological consequences of light pollution on juvenile bonefish. Due to their apparent utilization of nearshore habitats (i.e., evidence from fish seines; Sogard et al. 1989; Layman \& Silliman 2002), it is likely juvenile bonefish are exposed to anthropogenic disturbances, particularly in places like southeast Florida where there has been substantial coastal development (Finkl \& Charlier 2003). The results of the behavioural component of my study suggest that there is little effect from either source of artificial light pollution on juvenile bonefish swimming behaviour, although the results from the overnight physiology component of the study suggest there were changes to their blood glucose. Following the overnight treatments, juvenile bonefish in the intermittent and constant light treatments had elevated blood glucose concentrations compared to the control group. The constant light treatment had significantly higher blood glucose than the control and intermittent group; although the intermittent treatment was not statistically significant, there was evidence of blood glucose being elevated with increasing exposure to artificial light. There was no evidence of a change in cortisol, a common finding among photoperiod manipulation studies (Brüning et al. 2015; Biwas et al. 2006, 2008). Cortisol becomes rapidly elevated following a stressor, but often returns to baseline levels within $4 \mathrm{hr}$ (Barton 2002); therefore, it is a possibility that there was a cortisol response immediately following exposure to light, but that it was indiscernible some $8 \mathrm{hr}$ later. Due to the apparent low numbers of juvenile bonefish along the 
developed coast of southeast Florida (Adams et al. 2008, Snodgrass et al. 2008), studying the impacts of coastal development and anthropogenic disturbances is a critical research area to focus on. Conducting further research on the impacts of coastal development on juvenile bonefish may inform managers and refine potential causes of the low number of juvenile bonefish and subsequent decreasing population of adults in Florida (Adams et al. 2008; Snodgrass et al. 2008; Adams et al. 2014). In a broader context, this study is the first to specifically look at the effects of light pollution on juvenile fish in a marine system. There is a growing body of literature explicitly tailored to consider the associated disturbances of artificial light pollution (e.g., Longcore \& Rich 2004; Navara \& Nelson 2007). Evidence across various taxa suggests artificial light pollution results in disturbance to spatial orientation, foraging patterns, migration, reproduction, predation, and communication (all reviewed in Longcore \& Rich 2004). Further research on juvenile bonefish and other nearshore species is required to determine whether marine fish experience similar disturbances.

\section{4-1.2: Future Research Opportunities}

This thesis contributes an important initial examination of juvenile bonefish behaviour and physiology, providing novel insights and foundational work necessary to explore future avenues of research. Based on the results from Chapter 2, further investigation should establish the behavioural and evolutionary drivers responsible for the association between juvenile bonefish and mojarra. Firstly, there should be a complementary field-based study to my experiment, to eliminate any associated tank effects, and emulate natural conditions as accurately as possible. As this study has suggested, mojarra are an important shoal mate for juvenile bonefish, thus future research should aim to more closely examine possible mechanisms to explain this relationship, with a focus on foraging opportunities and predator-prey relationships (i.e., does the relationship result in the oddity effect, or attack abatement). Based on the lack of significant alterations to juvenile bonefish swimming behaviour in Chapter 3, I propose a future study with chronic artificial light pollution (i.e., over 
several nights), as this is more indicative of what wild fishes are possibly experiencing in nearshore habitats. A long-term study could determine whether secondary responses (i.e., blood glucose) would eventually result in tertiary responses (i.e., swimming behaviour). Other important future avenues of research include addressing whether juvenile bonefish are attracted to- or repulsed by- artificial lighting. Following the results of such a study, research could be conducted on the foraging activity of juvenile bonefish during artificial lighting, and whether they are more at risk of predation. Increased photoperiods have resulted in increased feeding in some nearshore marine fish (Biwas et al. 2005, 2008); if future studies show this to be the case for juvenile bonefish, subsequent predation studies could elucidate whether they would suffer greater detection by predators due to sediment stirring while feeding on benthic invertebrates (Alexander 1961). Overall, I believe the next fundamental area of juvenile bonefish research should focus on habitat requirements in undisturbed environments. To this end, acoustic telemetry could be used to identify specific microhabitat usage of juvenile bonefish. Additionally, tagging mojarra alongside juvenile bonefish would be an excellent complement to the shoaling study in Chapter 2. Determining the habitat usage of juvenile bonefish could inform managers of their preferred habitats, and given their economic value as adults, could result in the protection of pristine environments or restoration of previously degraded ones.

\section{4-1.3: Conclusion}

The research conducted for my thesis yields the first insight into the behaviour and physiology of juvenile bonefish, a life stage that has been effectively disregarded in past research programs. To my knowledge there is currently no management in place specifically regarding juvenile bonefish, nor have they been involved in past management decisions. Adult bonefish have garnered the majority of attention from researchers and policy-makers, as this is the most economically lucrative life stage for this angled catch-and-release species (Fedler 2010). With the recent declines in the adult bonefish population and the IUCN's recent designation of 'near-threatened' (Adams et al. 2014), in 
combination with the difficulties of locating juvenile bonefish (Snodgrass et al. 2008), there is a call for a shift in research priorities to consider the juvenile life stage. Initiating research on the fundamental and applied aspects of juvenile bonefish behaviour is essential to begin understanding their natural history and specific life stage requirements. With further research, there may be evidence to inform managers of specific juvenile bonefish requirements, thereby necessitating conservation and management actions that differ from their adult life stage. Results from my thesis provide novel insights into the juvenile life stage of bonefish, and offer a foundational framework from which future research can build upon. 


\section{References}

Adams AJ, Wolfe RK, Tringali MD, Wallace EM, Kellison GT (2008) Rethinking the status of Albula spp. biology in the Caribbean and Western Atlantic. In: Ault, J.S. (Ed.), Biology and management of the world tarpon and bonefish fisheries. CRC Press, Boca Raton, Florida, pp. 203214.

Adams AJ, Horodysky AZ, Mcbride RS, Guindon K, Shenker J, Macdonald TC, Harwell HD, Ward R, Carpenter K (2014) Global conservation status and research needs for tarpons (Megalopidae), ladyfishes (Elopidae) and bonefishes (Albulidae). Fish Fish 15(2): 280-311.

Aguirre LF, Herrel A, Van Damme R, Matthysen E (2002) Ecomorphological analysis of trophic niche partitioning in a tropical savannah bat community. Proc R Soc Lond B Biol Sci 269(1497): $1271-1278$.

Albrecht M, Gotelli NJ (2001) Spatial and temporal niche partitioning in grassland ants. Oecol 126(1): $134-141$.

Alexander EC (1961) A contribution to the life history, biology and geographical distribution of the bonefish, Albula vupes (Linnaeus).

Amundsen T, Forsgren E (2001) Male mate choice selects for female coloration in a fish. PNAS 98(23): 13155-13160.

Baker R, Sheaves M (2007) Shallow-water refuge paradigm: conflicting evidence from tethering experiments in a tropical estuary. Mar Ecol-Prog Ser 349: 13-22.

Barbier E, Hacker SD (2011) The value of estuarine and coastal ecosystem services. Ecol Monogr 81: $169-193$. 
Barton BA, Iwama GK (1991) Physiological changes in fish from stress in aquaculture with emphasis on the response and effects of corticosteroids. Annu Rev Fish Dis. 1: 3-26.

Barton BA (2002) Stress in fishes: a diversity of responses with particular reference to changes in circulating corticosteroids. Integr Comp Biol. 42(3): 517-525.

Bass J, Takahashi JS (2010) Circadian integration of metabolism and energetics. Science. 330(6009): $1349-1354$.

Beck MW, Heck Jr KL, Able KW, Childers DL, Eggleston DB, Gillanders BM ... Orth RJ (2001) The identification, conservation, and management of estuarine and marine nurseries for fish and invertebrates: a better understanding of the habitats that serve as nurseries for marine species and the factors that create site-specific variability in nursery quality will improve conservation and management of these areas. Bioscience 51(8): 633-641.

Bilkovic DM, Roggero MM (2008) Effects of coastal development on nearshore estuarine nekton communities. Mar Ecol-Prog Ser 358: 27-39.

Blumstein D, Daniel JC (2007) Quantifying Behavior the JWatcher Way. Sinauer Associates, Inc. Sunderland, MA. pp. 211

Bolnick DI (2001) Intraspecific competition favours niche width expansion in Drosophila melanogaster. Nature 410(6827): 463-466.

Braun CB, Grande T (2008) Evolution of peripheral mechanisms for the enhancement of sound reception. In Springer Handbook of Auditory Research. Fish Bioacoustics, Vol. 32 (ed. AN Popper, RR Fay, JF Webb), pp. 99-144. New York: Springer-Verlag. 
Brownscombe JW, Thiem JD, Hatry C, Cull F, Haak CR, Danylchuk AJ, Cooke SJ (2013) Recovery bags reduce post-release impairments in locomotory activity and behaviour of bonefish (Albula spp.) following exposure to angling-related stressors. J Exp Mar Biol Ecol 440: 207-215.

Brownscombe JW, Gutowsky LF, Danylchuk AJ, Cooke SJ (2014) Foraging behaviour and activity of a marine benthivorous fish estimated using tri-axial accelerometer biologgers. Mar Ecol Prog Ser 505: 241-251.

Brownscombe JW, Griffin L, Gagne T, Haak CR, Cooke SJ, Danylchuk AJ (2015) Physiological stress and reflex impairment of recreationally angled bonefish in Puerto Rico. Environ Biol Fishes. 98(11): 2287-2295.

Burke L, Kura Y, Kassem K, Revenga C, Spalding M, McAllister D (2000) Pilot analysis of global ecosystems: Coastal Ecosystems Technical Report. Washington, D.C.: World Resources Institute Clark CW, Mangel M (1986) The evolutionary advantages of group foraging. Theor Popul Biol 30(1): $45-75$.

Clark TD, Donaldson MR, Drenner SM, Hinch SG, Patterson DA, Hills J, Ives V, Carter JJ, Cooke SJ, Farrell AP (2011) The efficacy of field techniques for obtaining and storing blood samples from fishes. J Fish Biol 79: 1322-1333.

Clutton-Brock T (2002) Breeding together: kin selection and mutualism in cooperative vertebrates. Science 296(5565): 69-72.

Cook KV, Lennox RJ, Hinch SG, Cooke SJ (2015) Fish out of water: How much air is too much? Fisheries. 40:452-461. 
Cooke SJ, Philipp DP (2004) Behavior and mortality of caught-and-released bonefish (Albula spp.) in Bahamian waters with implications for a sustainable recreational fishery. Biol Conserv 118: 599-607.

Cote J, Fogarty S, Sih A (2012) Individual sociability and choosiness between shoal types. Anim Behav 83(6): 1469-1476.

Couzin ID, Krause J, Franks NR, Levin SA (2005) Effective leadership and decision-making in animal groups on the move. Nature 433(7025): 513-516.

Crutzen PJ, Stoermer EF (2000) The ‘Anthropocene'. IGBP Newsletter 4: 17-18.

Cull F, Suski CD, Shultz A, Danylchuk AJ, O’Connor CM, Murchie KJ, Cooke SJ (2015)

Consequences of experimental cortisol manipulations on the thermal biology of the checkered puffer (Sphoeroides testudineus) in laboratory and field environments. J Therm Biol 47: 63-74.

Dall SRX, Johnstone RA (2002) Managing uncertainty: information and insurance under the risk of starvation. Philos. Trans. R. Soc. Lond. Ser. B 357: 1519-1526

Dall SR, Giraldeau LA, Olsson O, McNamara JM, Stephens DW (2005) Information and its use by animals in evolutionary ecology. Trends Ecol Evol 20(4): 187-193.

Danchin É, Giraldeau LA, Valone TJ, Wagner RH (2004) Public information: from nosy neighbors to cultural evolution. Science 305(5683): 487-491.

Danylchuk AJ, Danylchuk SE, Cooke SJ, Goldberg TL, Koppelman JB, Philipp DP (2007) PostRelease mortality of bonefish, Albula vulpes, exposed to different handling practices during catchand-release angling in Eleuthera, The Bahamas. Fisheries Manag Ecol. 14: 149-154.

Davies TW, Duffy JP, Bennie J, Gaston KJ (2014) The nature, extent, and ecological implications of marine light pollution. Front Ecol Environ 12(6): 347-355. 
Depledge MH, Godard-Codding CA, Bowen RE (2010) Light pollution in the sea. Mar Pollut Bull 60: 1383-85.

Dodd AN, Salathia N, Hall A, Kévei E, Tóth R, Nagy F, Hibberd JM, Millar AJ, Webb AAR (2005) Plant circadian clocks increase photosynthesis, growth, survival, and competitive advantage. Science 309(5734): 630-633.

Dolby AS, Grubb Jr TC (1998) Benefits to satellite members in mixed-species foraging groups: an experimental analysis. Anim Behav 56(2): 501-509.

Doll CN, Muller JP, Morley JG (2006) Mapping regional economic activity from night-time light satellite imagery. Ecol Econ 57: 75-92.

Domenici P,Wilson ADM, Kurvers RHJM, Marras S, Herbert-Read JE, Steffensen JF, Krause S, Viblanc PE, Couillaud P, Krause J (2014) How sailfish use their bills to capture schooling prey. Proc R Soc Lond [Biol] 281(1784) (DOI: 10.1098/rspb.2014.0444)

Dunlap JC (1999) Molecular bases for circadian clocks. Cell 96: 271- 290.

Elgar MA (1989) Predator vigilance and group size in mammals and birds: a critical review of the empirical evidence. Biol Rev 64(1): 13-33.

Ellison AM (2008) Managing mangroves with benthic biodiversity in mind: moving beyond roving banditry. J Sea Res 59: 2-15.

Fedler T (2010) The economic impact of flats fishing in The Bahamas. The Bahamian Flats Fishing Alliance 1-20. 
Finkl CW, Charlier RH (2003) Sustainability of Subtropical Coastal Zones in Southeastern Florida: Challenges for Urbanized Coastal Environments Threatened by Development, Pollution, Water Supply, and Storm Hazards. J Coast Res 19(4): 934-943.

Fitch JE (1950) Life history notes and the early development of the bonefish, Albula vulpes (Linnaeus). Calif. Fish Game 36(1): 3-6.

Fitzgibbon CD (1990) Mixed-species grouping in Thomson's and Grant's gazelles: the antipredator benefits. Anim Behav 39(6): 1116-1126.

Giraldeau LA, Beauchamp G (1999) Food exploitation: searching for the optimal joining policy. Trend Ecol Evol 14(3): 102-106.

Gliwicz ZM (1999) Predictability of seasonal and diel events in tropical and temperate lakes and reservoirs. In: Tundisi JG, Straskraba M (Eds). Theoretical reservoir ecology and its applications. São Carlos: International Institute of Ecology.

Gullström M, Bodin M, Nilsson PG, Öhman MC (2008) Seagrass structural complexity and landscape configuration as determinants of tropical fish assemblage composition. Mar Ecol-Prog Ser 363: 241255.

Halpern BS, Walbridge S, Selkoe KA, Kappel CV, Micheli F, D'Agrosa C, Bruno JF, Casey KS, Ebert C, Fox HE, Fujita R (2008) A global map of human impact on marine ecosystems. Science 319(5865), 948-952.

Hannesson R, Herrick S, Field J (2009) Ecological and economic considerations in the conservation and management of the Pacific sardine (Sardinops sagax). Can J Fish Aquat Sci 66: 859-868. 
Hannesson R, Herrick Jr SF (2010) The value of Pacific sardine as forage fish. Mar Policy 34: 935942.

Harrison NM, Whitehouse MJ (2011) Mixed-species flocks: an example of niche construction?. Anim Behav 81(4): 675-682.

Heldmaier G, Steinlechner S, Ruf T, Wiesinger H, Klingenspor M (1989) Photoperiod and thermoregulation in vertebrates: body temperature rhythms and thermogenic acclimation. J Biol Rhythms 4: 251-265.

Hoare DJ, Krause J (2003) Social organisation, shoal structure and information transfer. Fish Fish 4(3): 269-279.

Hoare DJ, Ruxton GD, Godin JGJ, Krause J (2000) The social organization of free-ranging fish shoals. Oikos 89(3): 546-554.

Hölker F, Moss T, Griefahn B, Griefahn B, Kloas W, Voigt CC (2010) The dark side of light: a transdisciplinary research agenda for light pollution policy. Ecol Soc 15: 13.

Hyndes GA, Platell ME, Potter IC (1997) Relationships between diet and body size, mouth morphology, habitat and movements of six sillaginid species in coastal waters: implications for resource partitioning. Mar Biol 128(4): 585-598.

Jackson JB, Kirby MX, Berger WH, Bjorndal KA, Botsford LW, Bourque BJ, Bradbury RH, Cooke R, Erlandson J, Estes JA, Hughes TP (2001) Historical overfishing and the recent collapse of coastal ecosystems. Science 293(5530): 629-637.

Jakle JA (2001) City lights. Illuminating the American night. John Hopkins University Press, Baltimore, Maryland, USA. 
Jud ZR, Layman CA, Shenker JM (2011) Diet of age-0 tarpon (Megalops atlanticus) in anthropogenically-modified and natural nursery habitats along the Indian River Lagoon, Florida. Environ Biol Fish 90(3): 223-233.

Kennish, MJ (2002) Environmental threats and environmental future of estuaries. Environ Conserv 29(01): 78-107.

Ko CH, Takahashi JS (2006) Molecular components of the mammalian circadian clock. Hum M Mol Gen. 15(suppl 2): R271-R277.

Krajewski JP, Bonaldo RM, Sazima C, Sazima I (2006) Foraging activity and behaviour of two goatfish species (Perciformes: Mullidae) at Fernando de Noronha Archipelago, tropical West Atlantic. Environ Biol Fish 77(1): 1-8.

Krause J, Butlin RK, Peuhkuri N, Pritchard VL (2000) The social organization of fish shoals: a test of the predictive power of laboratory experiments for the field. Biol Rev 75(4): 477-501.

Krause J, Ruxton GD (2002) Living in groups. Oxford University Press.

Labropoulou M, Eleftheriou A (1997) The foraging ecology of two pairs of congeneric demersal fish species: importance of morphological characteristics in prey selection. J Fish Biol 50(2): 324-340.

Lachlan RF, Crooks L, Laland KN (1998) Who follows whom? Shoaling preferences and social learning of foraging information in guppies. Anim Behav 56(1): 181-190.

Laegdsgaard P, Johnson C (2001) Why do juvenile fish utilise mangrove habitats? J Exp Mar Biol Ecol 257(2): 229-253.

Landeau L, Terborgh J (1986) Oddity and the 'confusion effect'in predation. Anim Behav 34(5): $1372-1380$. 
Larkin MF (2011) Assessment of South Florida's Bonefish Stock. University of Miami, Doctoral Dissertation, 194 pp.

Laskowski, KL, Bell AM (2014) Strong personalities, not social niches, drive individual differences in social behaviours in sticklebacks. Anim Behav 90: 287-295.

Layman CA, Silliman BR (2002) Preliminary survey and diet analysis of juvenile fishes of an estuarine creek on Andros Island, Bahamas. B Mar Sci 70(1): 199-210.

Longcore T, Rich C (2004) Ecological light pollution. Front Ecol Environ 2: 191-98.

Lotze HK, Lenihan HS, Bourque BJ, Bradbury RH, Cooke RG, Kay MC, Kidwell SM, Kirby MX, Peterson CH, Jackson JBC (2006) "Depletion, degradation, and recovery potential of estuaries and coastal seas." Science 312(5781): 1806-1809.

Lukoschek V, McCormick MI (2000) A review of multi-species foraging associations in fishes and their ecological significance. In Proceeding 9th International Coral Reef Symposium (Vol. 1, pp. 467474). Ministry of Environment, Indonesian Institute of Sciences and International Society for Reef Studies.

Macfarlane A, Haines A, Goubet S, Anderson R, Ponce de Leon A, Limb E (1841) Air pollution, climate and health: short-term effects and long-term prospects. The health of adult Britain 1994: 1997.

Marras S, Killen SS, Lindström J, McKenzie DJ, Steffensen JF, Domenici P (2015) Fish swimming in schools save energy regardless of their spatial position. Behav Ecol Sociobiol 69(2): 219-226.

Martínez ML, Intralawan A, Vázquez G, Pérez-Maqueo O, Sutton P, Landgrave R (2007) The coasts of our world: ecological, economic and social importance. Ecol Econ 63(2-3): 254-272. 
Menaker, M, Moreira LF, Tosini G (1997) Evolution of circadian organization in vertebrates. Braz J Med Biol Res 30(3): 305-313.

Modde T, Ross ST (1983) Trophic relationships of fishes occurring within a surf zone habitat in the northern Gulf of Mexico. NE Gulf Sci 6(2): 109-120.

Mommsen, TP, Vijayan, MM, Moon, TW (1999) Cortisol in teleosts: dynamics, mechanisms of action, and metabolic regulation. Rev. Fish Biol. Fisher 9(3): 211-268.

Morse DH (1977) Feeding behaviour and predator avoidance in heterospecific groups. Biosci 27: $332-339$.

Munsch SH, Cordell JR, Toft JD (2016) Fine-scale habitat use and behavior of a nearshore fish community: nursery functions, predation avoidance, and spatiotemporal habitat partitioning. Mar Ecol Prog Ser 557: 1-15.

Murchie KJ, Danylchuk SE, Pullen CE, Brooks E, Shultz AD, Suski CD, Danylchuk AJ, Cooke SJ. (2009) Strategies for the capture and transport of bonefish, Albula vulpes, from tidal creeks to a marine research laboratory for long-term holding. Aquac Res. 40(13):1538-1550.

Murchie KJ, Cooke SJ, Danylchuk AJ, Danylchuk SE, Goldberg TL, Suski CD, Philipp DP (2013) Movement patterns of bonefish (Albula vulpes) in tidal creeks and coastal waters of Eleuthera, The Bahamas. Fish Res 147: 404-412.

Nagelkerken I, Van der Velde G, Gorissen MW, Meijer GJ, Van't Hof T, Den Hartog C (2000) Importance of mangroves, seagrass beds and the shallow coral reef as a nursery for important coral reef fishes, using a visual census technique. Estuar Coast Shelf Sci 51(1): 31-44. 
Navara KJ, Nelson RJ (2007) The dark side of light at night: physiological, epidemiological, and ecological consequences. J Pineal Res 43(3): 215-224.

Nowell LB, Brownscombe JW, Gutowsky LFG, Murchie KJ, Suski CD, Danylchuk AJ, Shultz A, Cooke SJ (2015) Swimming energetics and thermal ecology of adult bonefish (Albula vulpes): A combined laboratory and field study in Eleuthera, The Bahamas. Environ Biol Fish 98: 2133-2146.

O'Sullivan C (2005) The importance of mangroves Available:

http://ufdcimages.uflib.ufl.edu/UF/00/09/34/46/00028/00028Mangroves.pdf

Ostrander GK (Ed.) 2000. The Laboratory Fish. San Diego, CA: Academic Press.

Packer C, Ruttan, L (1988) The evolution of cooperative hunting. Am Nat 132(2): 159-198.

Panda S, Hogenesch JB, Kay SA (2002) Circadian rhythms from flies to human. Nature 417(6886): $329-335$.

Paradis E, Claude J, Strimmer K (2004) APE: analyses of phylogenetics and evolution in R language. Bioinformatics 20: 289-290. doi: 10.1093/bioinformatics/btg412

Parmentier E, Mann K, Mann D (2011) Hearing and morphological specializations of the mojarra (Eucinostomus argenteus). J Exp Biol 214(16): 2697-2701.

Paterson AW, Whitfield AK (2000) Do shallow-water habitats function as refugia for juvenile fishes?. Estuar Coast Shelf S 51(3): 359-364.

Pavlov DS, Kasumyan AO (2000) Patterns and mechanisms of schooling behavior in fish: a review. J Ichthyol 40(2): S163-S231.

Peters KM, Matheson Jr, RE, Taylor RG (1998) Reproduction and early life history of common snook, Centropomus undecimalis (Bloch), in Florida. B Mar Sci 62(2): 509-529. 
Pickering AD, Pottinger TG, Christie P (1982) Recovery of the brown trout, Salmo trutta L., from acute handling stress: a time-course study. J Fish Biol 20(2): 229-244.

Pierce DJ, Mahmoudi B, Wilson RR (2001) Age and growth of the scaled herring, Harengula jaguana, from Florida waters, as indicated by microstructure of the sagittae. Fish Bull Nat Oc At 99(1): 202209.

Pinheiro J, Bates D, DebRoy S, Sarkar D, Team RC (2015)_nlme: Linear and nonlinear mixed effects models_. R package version 3.1-122. http://CRAN.R-project.org/package=nlme

Pitcher TJ (1986) Functions of shoaling behaviour in teleosts. In The behaviour of teleost fishes (pp. 294-337). Springer US.

Pitcher TJ, Parrish JK (1993) Functions of shoaling behaviour in teleosts. In: ed. T.J. Pitcher, Behaviour of Teleost Fishes. Chapman and Hall, London, pp. 363-440.

Pitman RL, Durban JW (2012) Cooperative hunting behavior, prey selectivity and prey handling by pack ice killer whales (Orcinus orca), type B, in Antarctic Peninsula waters. Mar Mam Sci 28(1): 1636.

Pleizier N, Wilson AD, Shultz AD, Cooke SJ (2015) Puffed and bothered: Personality, performance, and the effects of stress on checkered pufferfish. Physiol Behav 152: 68-78.

Polidoro BA, Carpenter KE, Collins L, Duke NC, Ellison AM, Ellison JC, Farnsworth EJ, Fernando ES, Kathiresan K, Koedam NE, Livingstone SR, Miyagi T, Moore GE, Nam VN, Ong JE, Primavera JH, Salmo SG, Sanciangco JC, Sukardjo S, Wang Y, Yong JWH (2010) The Loss of Species: Mangrove Extinction Risk and Geographic Areas of Global Concern. PLoS ONE 5(4): e10095. 
Qu, L (2015) varComp: Variance Component Models. R Package version 0.1-360. https://cran.rproject.org/web/packages/varComp/varComp.pdf

Radakov DV (1973) Schooling in the ecology of fish. John Wiley and Sons, New York.

Radford AN, Du Plessis MA (2003) Bill dimorphism and foraging niche partitioning in the green woodhoopoe. J Anim Ecol 72(2): 258-269.

Ragusa-Netto J (2002) Vigilance towards raptors by nuclear species in bird mixed flocks in a Brazilian savannah. Stud Neotrop Fauna E 37(3) 219-226.

Rasquin P (1955) Observations on the metamorphosis of the bonefish, Albula vulpes (Linnaeus). J Morphol 97(1): 77-117.

Reis-Filho, J. A., Barros, F., Da Costa, J. D. A. C., Sampaio, C. L. S., \& De Souza, G. B. G. (2011) Moon and tide effects on fish capture in a tropical tidal flat. J Mar Biol Assoc UK 91(3): 735-743.

Rotllant J, Tort L (1997) Cortisol and glucose responses after acute stress by net handling in the sparid red porgy previously subjected to crowding stress. J Fish Biol 51(1): 21-28.

Rudd MA, Lawton RN (2013) Scientists' prioritization of global coastal research questions. Mar Pol 39: 101-11.

Salmon M, Witherington BE (1995) Artificial lighting and seafinding by loggerhead hatchlings: evidence for lunar modulation. Copeia 1995: 931-938.

Sazima I (1986) Similarities in feeding behaviour between some marine and freshwater fishes in two tropical communities. J Fish Biol 29: 53-65.

Sazima I (2002). Juvenile snooks (Centropomidae) as mimics of mojarras (Gerreidae), with a review of aggressive mimicry in fishes. Environ Biol Fish 65(1): 37-45. 
Sazima C, Krajewski JP, Bonaldo RM, Guimarães PR (2006) The goatfish Pseudupeneus maculatus and its follower fishes at an oceanic island in the tropical west Atlantic. J Fish Biol 69(3): 883-891.

Sazima C, Krajewski JP, Bonaldo RM, Sazima I (2007) Nuclear-follower foraging associations of reef fishes and other animals at an oceanic archipelago. Environ Biol Fish 80(4): 351-361.

Schafer LN, Platell ME, Valesini FJ, Potter IC (2002) Comparisons between the influence of habitat type, season and body size on the dietary compositions of fish species in nearshore marine waters. J Exp Mar Biol Ecol 278(1): 67-92.

Seitz RD, Wennhage H, Bergström U, Lipcius RN, Ysebaert T (2014) Ecological value of coastal habitats for commercially and ecologically important species. ICES J Mar Sci: J Conseil 71(3): 648665.

Seppänen JT, Forsman JT, Mönkkönen M, Thomson RL (2007) Social information use is a process across time, space, and ecology, reaching heterospecifics. Ecology 88(7): 1622-1633.

Sheridan PF (1992) Comparative habitat utilization by estuarine macrofauna within the mangrove ecosystem of Rookery Bay, Florida. B Mar Sci 50(1): 21-39.

Silverman ED, Veit RR, Nevitt GA (2004) Nearest neighbors as foraging cues: information transfer in a patchy environment. Mar Ecol Prog Ser 277: 25-35.

Siung-Chang A (1997) A review of marine pollution issues in the Caribbean. Environ Geochem Hlth 19(2): 45-55.

Snodgrass D, Crabtree RE, Serafy JE (2008) Abundance, growth, and diet of young-of-the-year bonefish (Albula spp.) off the Florida Keys, U.S.A. Bull Mar Sci 82: 185-193. 
Sogard SM, Powell GV, Holmquist JG (1989) Utilization by fishes of shallow, seagrass-covered banks in Florida Bay: 1. Species composition and spatial heterogeneity. Environ Biol Fish 24(1): $53-$ 65.

Sridhar H, Beauchamp G, Shanker K (2009) Why do birds participate in mixed-species foraging flocks? A large-scale synthesis. Anim Behav 78(2): 337-347.

Stensland EVA, Angerbjörn A, Berggren PER (2003) Mixed species groups in mammals. Mam Rev 33(3-4): 205-223.

Stewart KM, Bowyer RT, Kie J, Dick BL, Ben-David M (2003) Niche partitioning among mule deer, elk, and cattle: do stable isotopes reflect dietary niche? Ecosci 10(3): 297-302.

Stoot LJ, Cairns NA, Cull F., Taylor JJ, Jeffrey JD, Morin F, Mandelman JW, Clark TD, Cooke SJ (2014) Use of portable blood physiology point-of-care devices for basic and applied research on vertebrates - a review. Conserv Physiol. 2: cou11 DOI: 10.1093/conphys/cou011

Székely T, Szép T, Zuhas T (1989) Mixed-species flocking of tits (Parus spp.): a field experiment. Oecol 78: 490-495.

Szekeres P, Brownscombe JW, Cull F, Danylchuk AJ, Shultz AD, Suski CD, Murchie KJ, Cooke SJ (2014) Physiological and behavioural consequences of cold shock on bonefish (Albula vulpes) in The Bahamas. J Exp Mar Bio Ecol 459: 1-7.

Team RC (2015) R: A language and environment for statistical computing. R Foundation for Statistical Computing, Vienna, Austria. http://www.R-project.org/

Teixeira RL, Helmer JL (1998) Ecology of young mojarras (Pisces: Gerreidae) occupying the shallow waters of a tropical estuary. Rev Brasil Biol 57: 637-646. 
Turner AM, Montgomery SL (2003) Spatial and temporal scales of predator avoidance: experiments with fish and snails. Ecology 84(3): 616-622.

Turner GF, Pitcher TJ (1986) Attack abatement: a model for group protection by combined avoidance and dilution. Am Nat 128(2): 228-240.

Valiela I, Bowen JL, York JK (2001) Mangrove forests: one of the world's threatened major tropical environments. BioScience 51: 807-815.

Veen T, Borge T, Griffith SC, Saetre GP, Bures S, Gustafsson L, Sheldon BC (2001) Hybridization and adaptive mate choice in flycatchers. Nature 411(6833): 45-50.

Vega-Cendejas ME, Hernández M, Arreguin-Sanchez F (1994) Trophic interrelations in a beach seine fishery from the northwestern coast of the Yucatan peninsula, Mexico. J Fish Biol 44(4): 647-659.

Vijayan MM, Pereira C, Grau EG, Iwama GK (1997) Metabolic responses associated with confinement stress in tilapia: the role of cortisol. Comp Biochem Physiol C Toxicol Pharmacol 116(1): 89-95.

Vinogradova IA, Anisimov VN, Bukalev AV, Semenchenko AV, Zabezhinski MA (2009) Circadian disruption induced by light-at-night accelerates aging and promotes tumorigenesis in rats. Aging 1(10): 855-865.

Vitousek PM, Mooney HA, Lubchenco J, Melillo JM (1997) Human domination of Earth's ecosystems. Science 277(5325): 494-499.

Warnes GR, Bolker B, Bonebakker L, Gentleman R, Liaw WHA, Lumley T, Maechler M, Magnusson A, Moeller S, Schwartz M, Venables B (2015) gplots: Various R programming tools for plotting data. R package version 2.16.0. http://CRAN.R-project.org/package=gplots 
Waycott M, Duarte CM, Carruthers TJ, Orth RJ, Dennison WC, Olyarnik S, Calladine A, Fourqurean JW, Heck KL, Hughes AR, Kendrick GA (2009) Accelerating loss of seagrasses across the globe threatens coastal ecosystems. P Natl A Sci 106(30): 12377-12381.

Webster MM, Hart PJ (2006) Kleptoparasitic prey competition in shoaling fish: effects of familiarity and prey distribution Behav Ecol 17(6): 959-964.

Weimerskirch H, Martin J, Clerquin Y, Alexandre P, Jiraskova S (2001) Energy saving in flight formation. Nature 413(6857): 697-698.

Werner EE, Gilliam JF, Hall DJ, Mittlebach GG (1983) An experimental test of the effects of predation risk on habitat use in fish. Ecology 64(6): 1540-1548.

Wilkinson C (2000) Status of Coral Reefs of the World 2000, Australian Institute of Marine Science (AIMS), Global Coral Reef Monitoring Network (GCRMN), Townsville, Australia

Wilson ADM, Krause J (2013) Repeated non-agonistic interactions between a bottlenose dolphin (Tursiops truncatus) and sperm whales (Physeter macrocephalus) in Azorean Waters. Aquat Mamm 39: 89-96.

Wolf M, Weissing FJ (2012) Animal personalities: consequences for ecology and evolution. Trend Ecol Evol 27(8): 452-461.

Worm B, et al. (2006) Impacts of biodiversity loss on ocean ecosystem services. Science 314:787790.

Wright D, Krause J (2006) Repeated measures of shoaling tendency in zebrafish (Danio rerio) and other small teleost fishes. Nat Protoc 1(4): 1828-1831. 
Zahorcsak P, Silvano RAM, Sazima I (2000) Feeding biology of a guild of benthivorous fishes in a sandy shore on south-eastern Brazilian coast. Rev Bras Biol 60(3): 511-518.

Zuur AF, Ieno EN, Walker NJ, Saveliev AA, Smith GM (2009) GLM and GAM for count data. In Mixed effects models and extensions in ecology with $R$ (pp. 209-239). Springer New York. 